\title{
Deformation Structure and Subsurface Fatigue Crack Generation in Austenitic Steels at Low Temperature
}

\begin{abstract}
OSAMU UMEZAWA and KOTOBU NAGAI
In order to progress in the understanding of fatigue crack generation for high-strength alloys, the subsurface fatigue crack initiation sites were characterized and the deformation structure was investigated for the solution-treated $24 \mathrm{Cr}-15 \mathrm{Ni}-4 \mathrm{Mn}-0.3 \mathrm{~N}$ and $32 \mathrm{Mn}-7 \mathrm{Cr}-0.1 \mathrm{~N}$ austenitic steels. Highcycle fatigue tests of those steels were carried out at 4, 77, and $293 \mathrm{~K}$. Subsurface crack initiation was detected in the lower-peak stress and/or in the longer-life range at the three temperatures. The subsurface crack initiation sites were intergranularly formed. The localized deformation and/or strain concentration by dislocation arrays of the (111)- $\langle 110\rangle$ system assisted intergranular cracking due to incompatibility at grain boundaries. Dislocation movements were restricted to their slip planes. Even at the lower stress level, dislocations had generated in more than one slip system and piled up to a grain boundary. The peak cyclic stress was lowered with the increasing size of the subsurface crack initiation site. The dependence of the subsurface crack size on the peak cyclic stress was discussed.
\end{abstract}

\section{INTRODUCTION}

OUR research group has investigated the cryogenic high-cycle fatigue properties of some alloys, like titanium alloys and austenitic steels, which are the candidate materials for cryogenic structural use. ${ }^{[1,2]}$ In general, fatigue crack initiation is understood to occur on the specimen surface owing to the irreversible process of extrusion and intrusion through slip deformation. ${ }^{[3]}$ Most of the tested materials, however, clearly exhibited two kinds of fatigue crack initiation. ${ }^{[4]}$ One was at the specimen surface, and the other was in the specimen interior. The subsurface crack initiation was dominant in the long-life range and at lower temperatures, while the surface crack initiation occurred in high-peak stress tests and in short-life tests. It is revealed that the initiation site shifts from the surface to the interior at lower stress and that the subsurface crack initiation behavior can be clearly detected at cryogenic temperatures. Generally, the tensile strength of alloys is increased as the temperature is decreased. It appears that low-temperature fatigue tests make clear the features of fatigue crack generation behavior in high-strength alloys such as the Ti-6Al$4 \mathrm{~V}$ alloy. ${ }^{[5]}$

Nitrogen-strengthened $24 \mathrm{Cr}-15 \mathrm{Ni}^{[6]}$ and $32 \mathrm{Mn}-7 \mathrm{Cr}^{[7]}$ austenitic steels were designed to have high yield strength, improved toughness, and a high stability of austenite (fcc) phase at $4 \mathrm{~K}$. In particular, $24 \mathrm{Cr}-15 \mathrm{Ni}$ steel has a good balance of strength and toughness at $4 \mathrm{~K}$. Few studies have been done for the low-cycle fatigue behavior of those steels. The $32 \mathrm{Mn}-7 \mathrm{Cr}$ steel containing carbon and nitrogen showed low-cycle fatigue softening, which corresponded to the planar dislocation structure..$^{[8]}$ The $24 \mathrm{Cr}-15 \mathrm{Ni}$ steel also exhibited low-cycle fatigue softening at $4 \mathrm{~K} \cdot{ }^{[9]}$ However, there have been almost no studies performed on the sub-

OSAMU UMEZAWA is Senior Scientist with Frontier Research Center for Structural Materials, National Research Institute for Metals, Sengen, Tsukuba, Ibaraki 305, Japan. KOTOBU NAGAI is Group Leader with Frontier Research Center for Structural Materials, National Research Institute for Metals, Sengen, Tsukuba, Ibaraki 305, Japan.

Manuscript submitted March 11, 1997. surface fatigue crack generation due to intergranular cracking in austenitic steel at low temperatures.

At low-temperature, high-cycle fatigue, where the lattice dislocations blocked by a grain boundary are unable to climb, most of the dislocations will remain in place at the boundaries. The planar dislocation structures have been observed in austenitic steels and titanium alloys. ${ }^{[4]}$ In the investigation of the subsurface crack initiation for a Ti-5Al-2.5Sn ELI (extra low interstitials) alloy, the present authors pointed out not only that the localized deformation and/or strain concentration by dislocation pileups in the vicinity of grain boundaries were a potential source of microcracking, ${ }^{[10]}$ but also that a specific region with microstructural inhomogeneity provides a potential site against strain incompatibility and microcrack generation. ${ }^{[11]}$ Hence, it is important to make clear the correspondence between the fatigue crack initiation site and microstructure from the viewpoint of heterogeneity in both microstructure and deformation structure. To evaluate fatigue crack generation, furthermore, it is necessary to consider the size of the subsurface crack initiation site. The size mostly reflects the stress concentration at the stage I crack tip required to start its propagation as a fatal crack (stage II).

The objective of the present article is to identify the features of subsurface fatigue crack initiation in austenitic steels containing $\mathrm{Mn}$ and to discuss the concept for stage I crack formation, in order to better understand fatigue crack initiation in high-strength alloys. Therefore, the subsurface fatigue crack initiation sites are characterized and the deformation structure is investigated for the fatigue.

\section{EXPERIMENTAL}

\section{A. Materials}

Two kinds of austenitic steels, $24 \mathrm{Cr}-15 \mathrm{Ni}-4 \mathrm{Mn}-0.3 \mathrm{~N}$ $(24 \mathrm{Cr}-15 \mathrm{Ni})$ and $32 \mathrm{Mn}-7 \mathrm{Cr}-0.1 \mathrm{~N}(32 \mathrm{Mn}-7 \mathrm{Cr})$, which were developed for the cryogenic application, were examined in a solution-treated condition. The chemical compositions of each steel are listed in Table I. The $24 \mathrm{Cr}-15 \mathrm{Ni}$ high-Cr-Ni stainless steel was forged by a 50 -ton electrical furnace, hot 
Table I. Chemical Compositions of Tested Steels in the Present Study

\begin{tabular}{|c|c|c|c|c|c|c|c|c|c|c|c|c|c|}
\hline \multirow[b]{2}{*}{ Steel } & \multicolumn{13}{|c|}{ Concentration (Mass Pct) } \\
\hline & $\mathrm{C}$ & $\mathrm{Si}$ & $\mathrm{Mn}$ & $\mathrm{P}$ & $S$ & $\mathrm{Ni}$ & $\mathrm{Cr}$ & Mo & $\mathrm{Al}$ & $\mathrm{N}$ & $\mathrm{Ca}$ & $\mathrm{O}$ & $\mathrm{Fe}$ \\
\hline $24 \mathrm{Cr}-15 \mathrm{Ni}$ & 0.022 & 0.97 & 4.14 & 0.026 & 0.0009 & 14.74 & 24.43 & - & 0.011 & 0.330 & 0.002 & 0.0030 & bal \\
\hline $32 \mathrm{Mn}-7 \mathrm{Cr}$ & 0.14 & 0.60 & 31.58 & 0.022 & 0.006 & 0.23 & 7.04 & 0.04 & 0.012 & 0.133 & - & - & bal \\
\hline
\end{tabular}

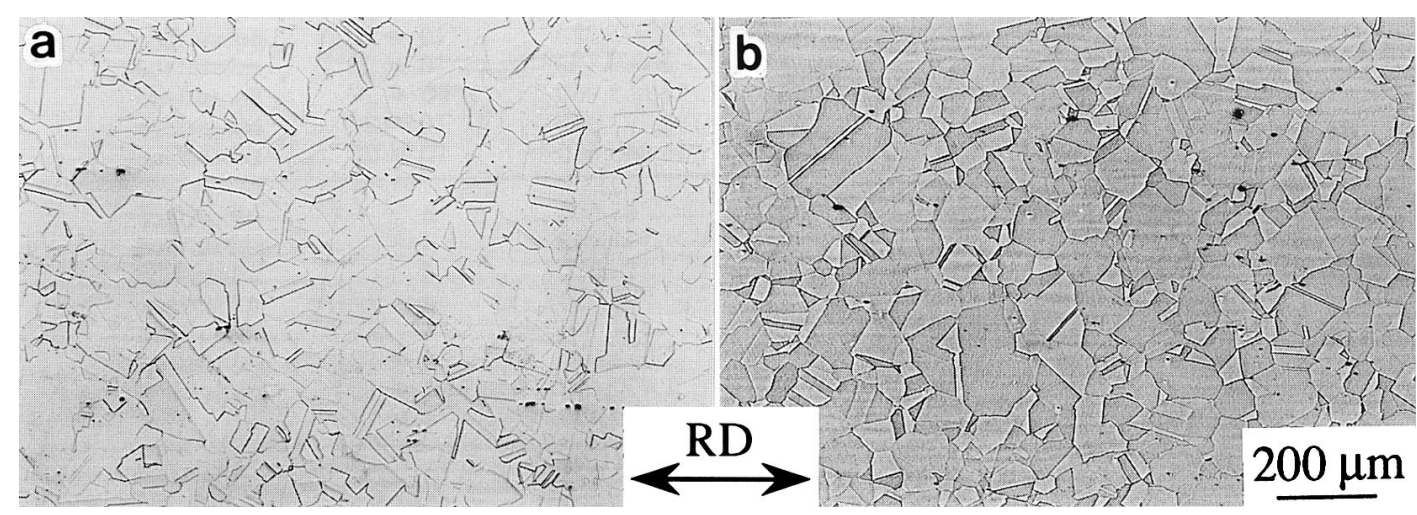

Fig. 1-Optical microstructures of (a) $24 \mathrm{Cr}-15 \mathrm{Ni}$ and (b) $32 \mathrm{Mn}-7 \mathrm{Cr}$ steels in the TD plane section.

Table II. Tensile Properties and Toughness of the Tested Steels at Cryogenic Temperatures

\begin{tabular}{|c|c|c|c|c|c|c|c|}
\hline Steel & $\begin{array}{c}\text { Temperature } \\
(\mathrm{K})\end{array}$ & $\begin{array}{l}\text { UTS } \\
(\mathrm{MPa})\end{array}$ & $\begin{array}{c}\mathrm{YS} \\
(\mathrm{MPa})\end{array}$ & $\begin{array}{c}\mathrm{El} \\
(\mathrm{Pct})\end{array}$ & $\begin{array}{l}\mathrm{RA} \\
\text { (Pct) }\end{array}$ & $\begin{array}{c}\text { CVN } \\
(\mathrm{J})\end{array}$ & $\begin{array}{c}K_{I C}(\mathrm{~J}) \\
(\mathrm{MPa} \sqrt{\mathrm{m}})\end{array}$ \\
\hline \multirow[t]{3}{*}{$24 \mathrm{Cr}-15 \mathrm{Ni}$} & 4 & 1885 & 1308 & 18.3 & 41.1 & 150 & 211 \\
\hline & 77 & 1535 & 973 & 45.0 & 49.3 & 196 & - \\
\hline & 293 & 790 & 410 & 53.8 & 73.3 & 293 & - \\
\hline \multirow[t]{3}{*}{$32 \mathrm{Mn}-7 \mathrm{Cr}$} & 4 & 1417 & 1118 & 47.4 & 52.8 & 141 & 143 \\
\hline & 77 & 1074 & 690 & 75.1 & 57.7 & 164 & - \\
\hline & 293 & 557 & 293 & 71.1 & 79.7 & 263 & - \\
\hline
\end{tabular}

rolled to a 30-mm-thick plate, and solution treated at 1373 $\mathrm{K}{ }^{[6]}$ For the $32 \mathrm{Mn}-7 \mathrm{Cr}$ high-manganese steel, a cast ingot was forged and rolled at $1423 \mathrm{~K}$ into a $30-\mathrm{mm}$-thick plate, then solution treated at $1293 \mathrm{~K}$ for $7.2 \mathrm{Ks}$, followed by a water quench. ${ }^{[7]}$

Optical micrographs of each steel are represented in Figure 1. Table II summarizes the strength and toughness for the tested steels. Tensile tests were done at a strain rate of $8.33 \times 10^{-4} \mathrm{~s}^{-1}$ using a screw-driven-type tester. Cylindrical test pieces were cut parallel to the transverse direction (TD) for both steels; the gage geometry was $3.5 \mathrm{~mm}$ in diameter and $20 \mathrm{~mm}$ in length. The test temperatures were 4, 77, and $293 \mathrm{~K}$. The 0.2 pct proof stress (YS), ultimate tensile strength (UTS), elongation (El), and reduction of area (RA) were determined by duplicate tests. The Vnotched Charpy impact energy (CVN) was determined by duplicate tests at 4, 77, and $293 \mathrm{~K}$. The V-notched Charpy impact specimens $(10 \times 10 \times 55 \mathrm{~mm}, 2$-mm-depth notch $)$ were also machined parallel to the TD. The fracture toughness $\left(K_{I C}(J)\right)$ was determined by the unloading compliance method in accordance with ASTM E813-81 at $4 \mathrm{~K}$ using a servohydraulic test machine. Compact tension specimens with a thickness of $25 \mathrm{~mm}$ were machined so that the load axis was parallel to the TD. The fatigue precrack, with a length of 60 pct of the specimen thickness, was introduced at room temperature. Both steels reveal a high strength and good toughness at cryogenic temperatures.

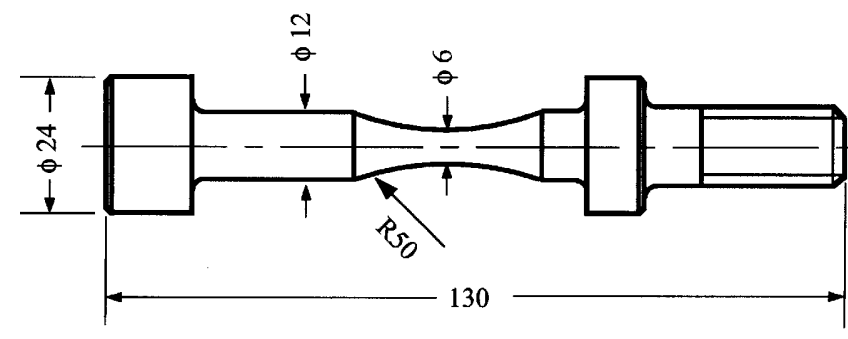

Fig. 2-Configuration of fatigue specimen in the present study.

\section{B. Fatigue Testing}

The test specimen configuration is shown in Figure 2; unnotched hourglass-type specimens with a waist diameter of $6 \mathrm{~mm}$ were used. The longitudinal direction of the specimens was perpendicular to the hot-rolling direction.

Fatigue testing was carried out in liquid helium (4 K), liquid nitrogen $(77 \mathrm{~K})$, and in ambient air (293 K). Using a cryogenic servohydraulic fatigue testing machine, ${ }^{[12]}$ load control tests were done. The sinusoidal waveform loading was uniaxial with a minimum-to-maximum stress ratio $(R)$ of 0.01 . Test frequencies of $4 \mathrm{~Hz}$ at $4 \mathrm{~K}$ and $10 \mathrm{~Hz}$ at 77 and $293 \mathrm{~K}$ were chosen so that the specimen temperature rise should be as low as possible. ${ }^{[13]}$ 
(a) Three-dimensional indication

(b) Projected on propagating plane

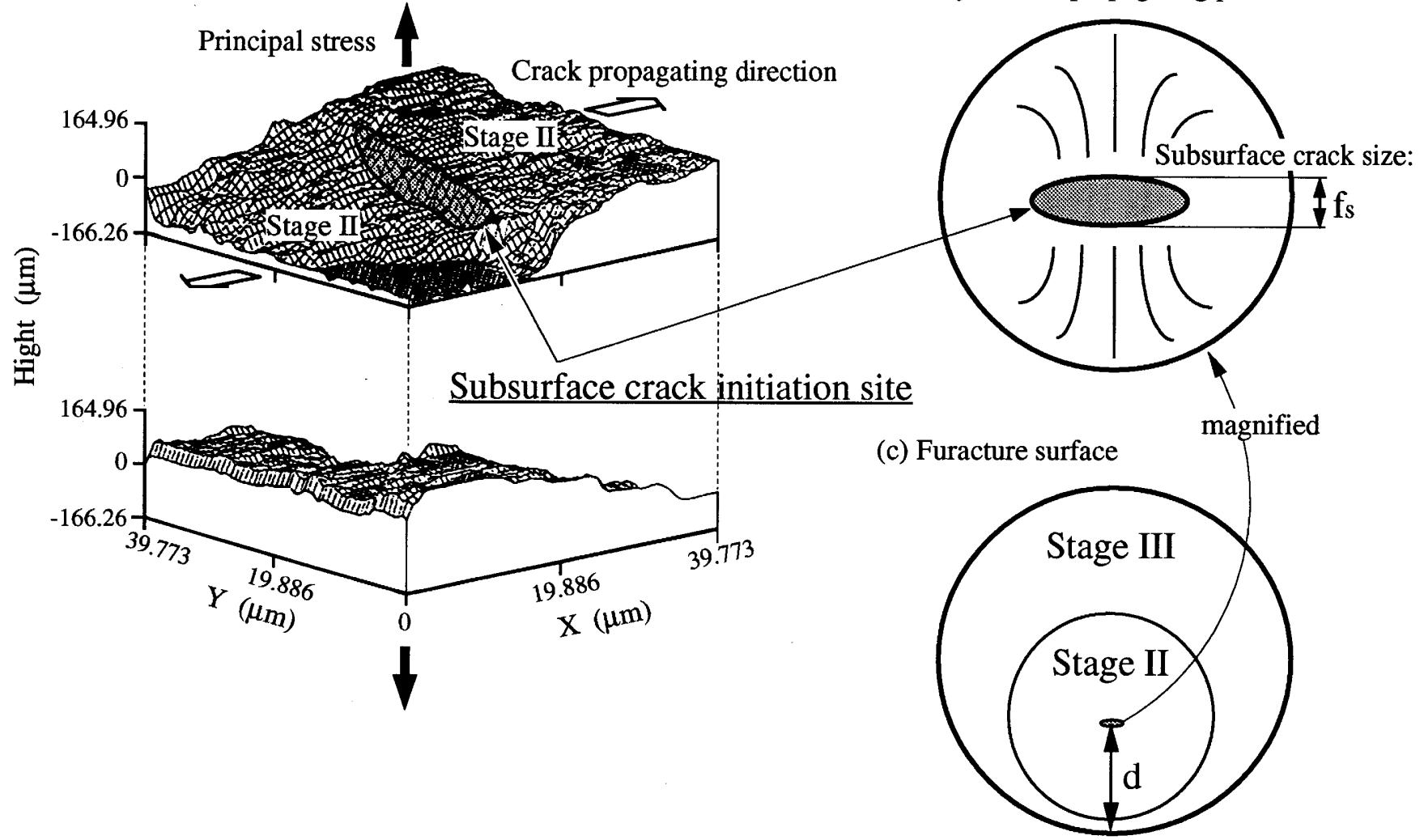

Fig. 3-(a) Three-dimensional indication of a subsurface crack initiation site, $(b)$ definition of subsurface crack size, $f_{s}$, as a geometric parameter, and $(c)$ depth of the initiation site, $d$, on the fracture surface.

\section{Microscopy and Characterization}

The subsurface crack initiation sites were examined by scanning electron microscopy (SEM). At low magnification, the subsurface crack initiation sites appeared flat and were inclined to the principal stress axis, as shown in Figure 3(a). In this study, the subsurface crack initiation site was defined as the whole of the inclined area which was not located on the fatigue crack-propagating plane. The size of the subsurface crack initiation site was quantified by a crack length parameter. The subsurface crack size $\left(f_{s}\right)$ was defined as the minor axis of an orthographic projection of the subsurface crack initiation site on the main crack (stage II)-propagating plane, as illustrated in Figure 3(b). ${ }^{[5]}$ The minor axis is almost parallel to the initial crack-propagating direction, and the stage II region is almost perpendicular to the principal stress axis. In the case of postulating the equivalent crack projected on the propagating plane, $f_{s}$ corresponds to its length. In addition, the depth $(d)$ from the nearest specimen surface to the subsurface crack initiation site was evaluated on the SEM photographs of fracture surfaces, as illustrated in Figure 3(c).

After fatigue testing, disks about $600-\mu \mathrm{m}$ thick were sectioned from beneath the fracture surface. They were cut perpendicular to the principal stress axis and were reduced to about $100 \mu \mathrm{m}$ in thickness by abrasion with 600-grit emery paper. Disc diameters were measured, and the stress level (stress amplitude: $\sigma_{a}$ ) of each disk was calibrated. Transmission electron microscope (TEM) foils were prepared by a conventional electrical jet polishing technique in a stirred solution of 10 pct acetic acid and 90 pct meth- anol at about $240 \mathrm{~K}$. A JEOL* 2000FXII TEM equipped

*JEOL is a trademark of Japan Electron Optics Ltd., Tokyo.

with a double-tilt goniometer stage was employed at 200 $\mathrm{keV}$.

Orientation imaging microscopy (OIM*), which is based

*OIM is a trademark of System TSL, TexSEM Laboratories Inc., Draper, Utah.

on the electron backscatter diffraction method, was applied to determine the grain boundary characteristics in the microstructure.

\section{RESULTS}

\section{A. High-Cycle Fatigue Strength}

Figure 4 shows $\mathrm{S}-\mathrm{N}$ curves of $24 \mathrm{Cr}-15 \mathrm{Ni}$ and $32 \mathrm{Mn}-7 \mathrm{Cr}$ steels at three temperatures. Table II shows that as temperature decreases there is an increase in the strength of both alloys. For most steels, fatigue strength is proportional to tensile strength at room temperature. ${ }^{[14]}$ If this relationship applies at low temperatures, the fatigue strength should increase at low temperatures. However, there is hardly any difference between the S-N curves at 77 and $4 \mathrm{~K}$ over $10^{6}$ cycles, as seen in Figure 4(a). In fact, the S-N curves of $24 \mathrm{Cr}-15 \mathrm{Ni}$ steel at 4 and $77 \mathrm{~K}$ appear to overlap. The difference in the S-N curves between 293 and $77 \mathrm{~K}$ also becomes narrower as the number of cycles to failure $\left(N_{f}\right)$ increases. 


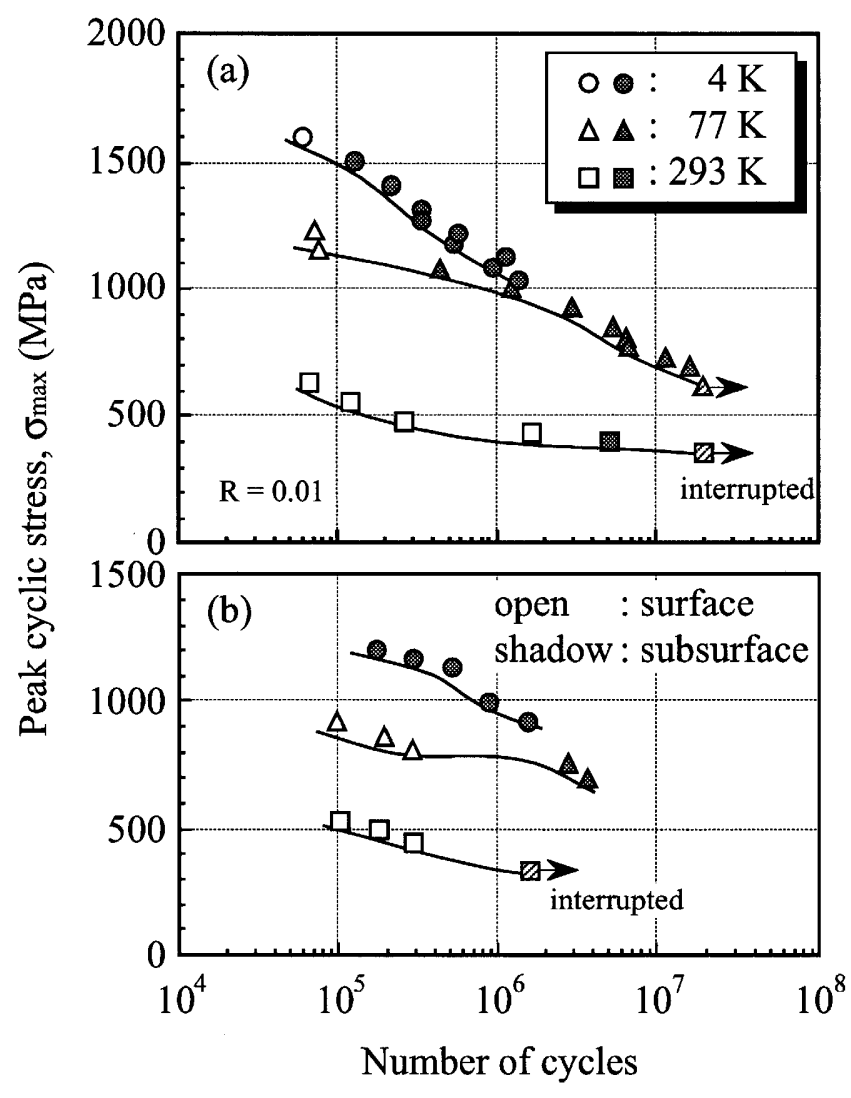

Fig. 4-S-N data of (a) $24 \mathrm{Cr}-15 \mathrm{Ni}$ and (b) $32 \mathrm{Mn}-7 \mathrm{Cr}$ steels at cryogenic temperatures.

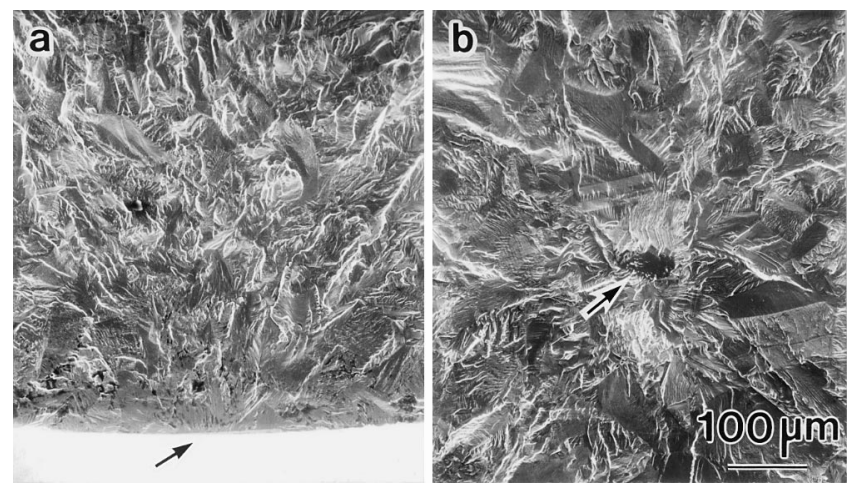

Fig. 5-SEM micrographs of fatigue crack initiation sites and fracture surfaces for $24 \mathrm{Cr}-15 \mathrm{Ni}$ samples failed at $4 \mathrm{~K}$ : (a) surface crack initiation, $\sigma_{\max }=1602 \mathrm{MPa}$; and $(b)$ subsurface crack initiation, $\sigma_{\max }=1132 \mathrm{MPa}$. The arrows show the location of crack initiation site.

\section{B. Crack Initiation Site and Its Location}

Subsurface crack initiation was detected in the lowerpeak stress and/or in the longer-life range, especially at lower temperatures. Their S-N data plots, in Figure 4, are distinguished between the specimen surface initiation and the subsurface initiation. For the $24 \mathrm{Cr}-15 \mathrm{Ni}$ steel, the fatigue crack initiation site shifted from the specimen surface to the specimen interior in the longer-life range at the three temperatures. On the other hand, all samples of the 32Mn$7 \mathrm{Cr}$ steel that fractured at $4 \mathrm{~K}$ show subsurface crack initiation. The fatigue crack initiation site at $77 \mathrm{~K}$ shifted from the specimen surface to the specimen interior at about $10^{6}$

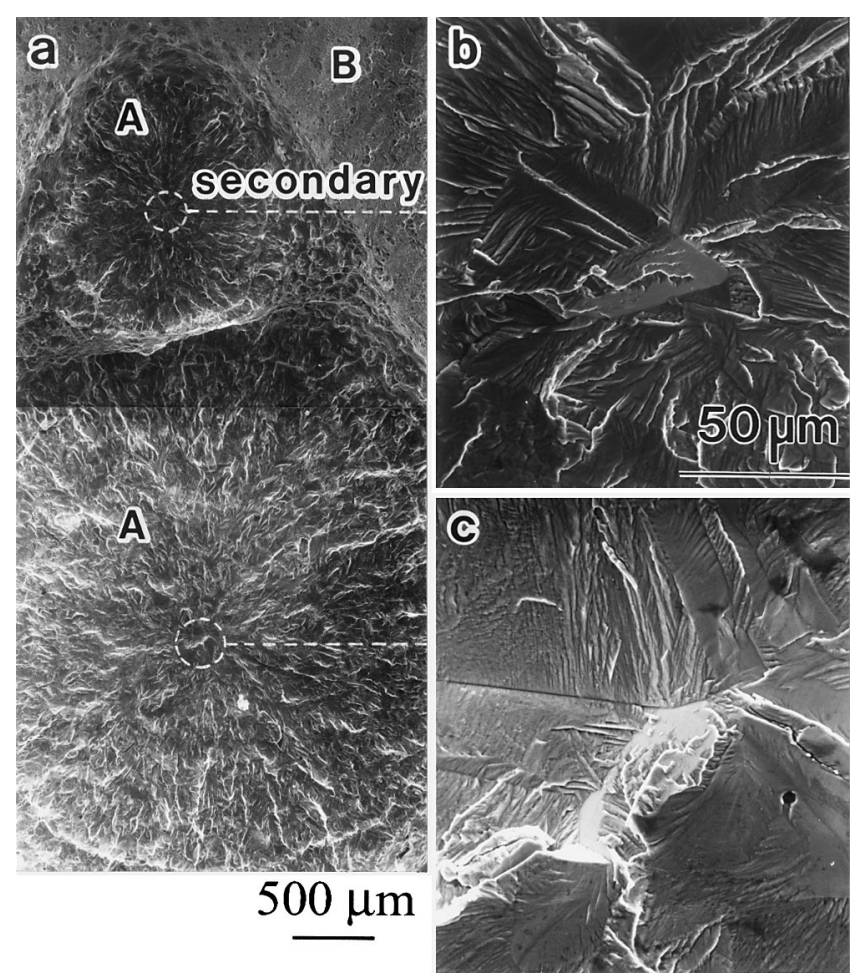

Fig. 6-SEM micrographs of the fracture surface and subsurface crack initiation site in a $24 \mathrm{Cr}-15 \mathrm{Ni}$ sample: $\sigma_{\max }=1414 \mathrm{MPa}$ at $4 \mathrm{~K}$. Photographs (b) and (c) are the magnified images of the initiation site for the secondary crack and the fatal crack, respectively.

cycles. In both steels, further, the sharp drop in fatigue strength over $10^{6}$ cycles at 4 and $77 \mathrm{~K}$, as seen in Figure 4 , is probably related to subsurface crack initiation failure.

The SEM photographs in Figure 5 represent the vicinity of the fatigue crack initiation site in samples which exhibited (a) surface crack initiation and (b) subsurface crack initiation at $4 \mathrm{~K}$ for $24 \mathrm{Cr}-15 \mathrm{Ni}$ steel. Figure 6 shows a fracture surface where two subsurface crack initiation sites appear in a sample failed at $4 \mathrm{~K}$ for $24 \mathrm{Cr}-15 \mathrm{Ni}$ steel. Figure 7 shows the fracture surface of samples failed at $4 \mathrm{~K}$ for $32 \mathrm{Mn}-7 \mathrm{Cr}$ steel. Region A indicates the fatigue crack-propagating plane, i.e., stage II, and region $\mathrm{B}$ indicates the rapid fracture surface covered with dimples, i.e., stage III. The location of the internal crack initiation site, indicated by the arrow, is almost at the center of the circular region A. The fatigue crack is radially propagating from the subsurface crack initiation site on stage II, and the ripple mark is revealed, as shown in Figures 6(a) and 7. The area or radius of the stage II region increased as the maximum stress decreased.

The subsurface crack initiation sites were located at different depths ranging from near zero (specimen surface) to $3 \mathrm{~mm}$ (specimen center). The location of the subsurface crack initiation site for both steels seems to be independent of stress level. Besides the subsurface crack initiation site, subcracks (microcracks) were initiated just below the stage II fracture surface in the longitudinal cross section of the failed specimen under various stress levels for the Ti-6Al$4 \mathrm{~V}$ alloys. ${ }^{[4]}$ In each steel, the subcracks could hardly be detected, although a secondary crack appears in Figure 6(a). 

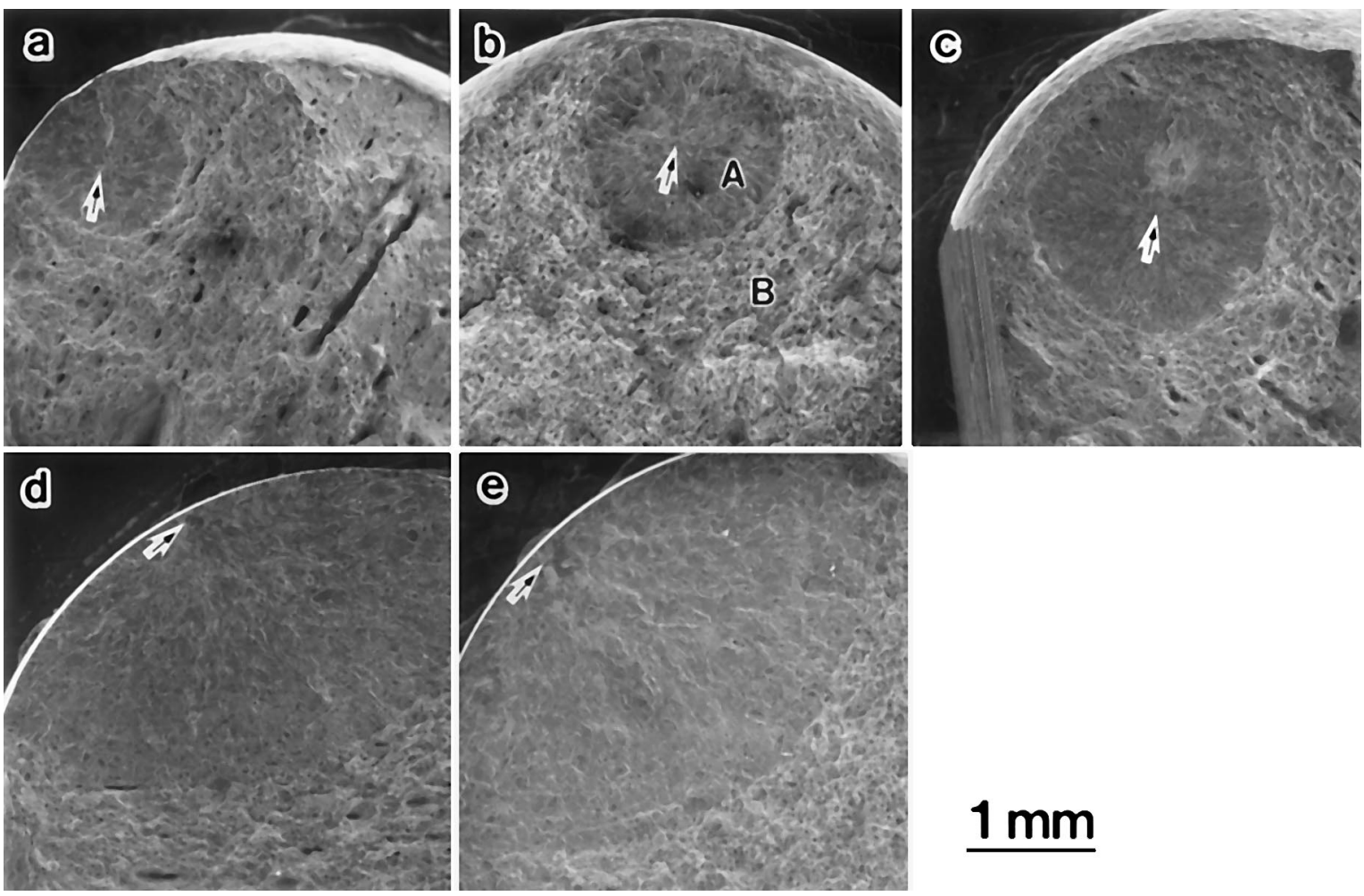

\section{$1 \mathrm{~mm}$}

Fig. 7-SEM photographs of the fracture surface of samples that failed at $4 \mathrm{~K}$ for $32 \mathrm{Mn}-7 \mathrm{Cr}$ steel: $(a) \sigma_{\max }=1204 \mathrm{MPa},(b) \sigma_{\max }=1169 \mathrm{MPa},(c) \sigma_{\max }$ $=1134 \mathrm{MPa},(d) \sigma_{\max }=992 \mathrm{MPa}$, and $(e) \sigma_{\max }=921 \mathrm{MPa}$. The arrows show the location of subsurface crack initiation sites.

\section{Morphology and Size of Subsurface Crack Initiation Site}

In both steels, no defects such as inclusions or pores were detected at the subsurface crack initiation sites, but one or more facets formed an initiation site. Transgranular fatigue microcracking is highly crystallographic, as is intergranular cracking. The most distinctive form of transcrystalline normal fracture is represented by cleavage. ${ }^{[15]}$ Cleavage fracture proceeds along definite crystal planes. It occurs in hexagonal and bcc metals but not in fcc ones. Then, terms such as intergranular cracking, quasicleavage, crystallographic decohesion, and slip plane decohesion have been employed to describe the microfractographic features.

Figure 8 presents the subsurface crack initiation site on the opposing fracture surfaces of a sample fatigued at $4 \mathrm{~K}$ in $32 \mathrm{Mn}-7 \mathrm{Cr}$ steel. Facets at the site match in an interlocking manner on the opposing fracture surfaces. Protrusions on a facet are also interlocked on matching surfaces. A grain boundary corner is observed, as indicated by the arrow in Figure 8.

At a higher maximum stress level, above 0.2 pct proof stress at $4 \mathrm{~K}$, subsurface crack initiation sites clearly display pits, protrusions, and line traces on facets, as shown in Figures 9 through 11. In fcc metals, near-threshold intergranular facets often present the small tetrahedra-like facets which appear as crystallographic pits and protrusions. ${ }^{[16]} \mathrm{In}$ Figures 9 and 10, the pits and protrusions are interlocked on matching surfaces. The shape of the triangular pits presented in Figure 10(c) also indicates that the three sides have a good correspondence to (111) slip planes and that one side of the pits is well aligned. On the other hand, the line traces in Figures 9(b) and 11 are accounted for in terms

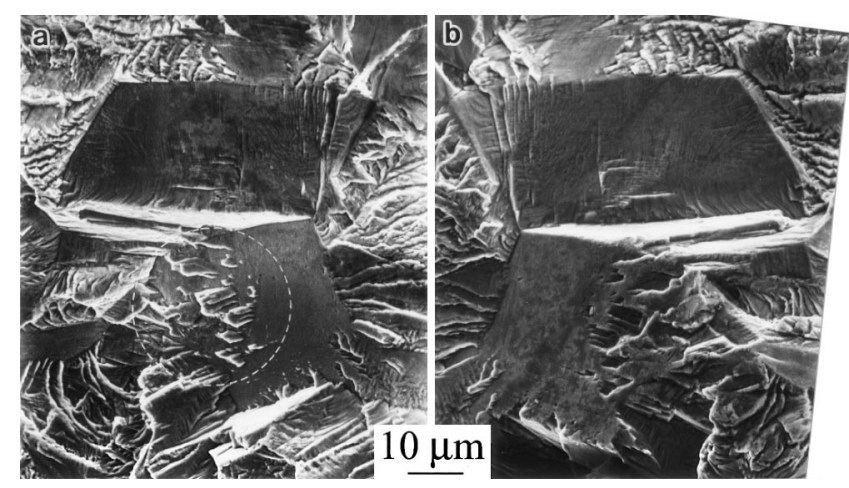

Fig. 8- (a) and (b) SEM matching-halves photographs of an initiation site of $32 \mathrm{Mn}-7 \mathrm{Cr}$ steel, which failed with $\sigma_{\max }=921 \mathrm{MPa}$ at $4 \mathrm{~K}$. The arrow shows a grain boundary corner. The dashed line circle indicates protrusions on the facet.

of the traces of the (111) slip line. The slip traces do not reveal symmetrical matching on opposing fracture surfaces.

It is believed that the protrusions and line traces on the facet, shown in Figures 9 through 11, formed before the crack surface (facet) formed. If transgranular cracking such as quasicleavage, crystallographic decohesion, and slip plane decohesion is employed, the mismatching of slip traces on the matching surfaces can hardly be explained. Hence, the presence of a grain boundary corner along facets, the mismatching of line traces on facets, and the interlocked manner of crystallographic pits are the reasons for identifying the subsurface crack initiation site as an intergranular facet or facets.

Figure 12 represents subsurface crack initiation sites of the $24 \mathrm{Cr}-15 \mathrm{Ni}$ samples failed at (a) $77 \mathrm{~K}$ and (b) $293 \mathrm{~K}$. 


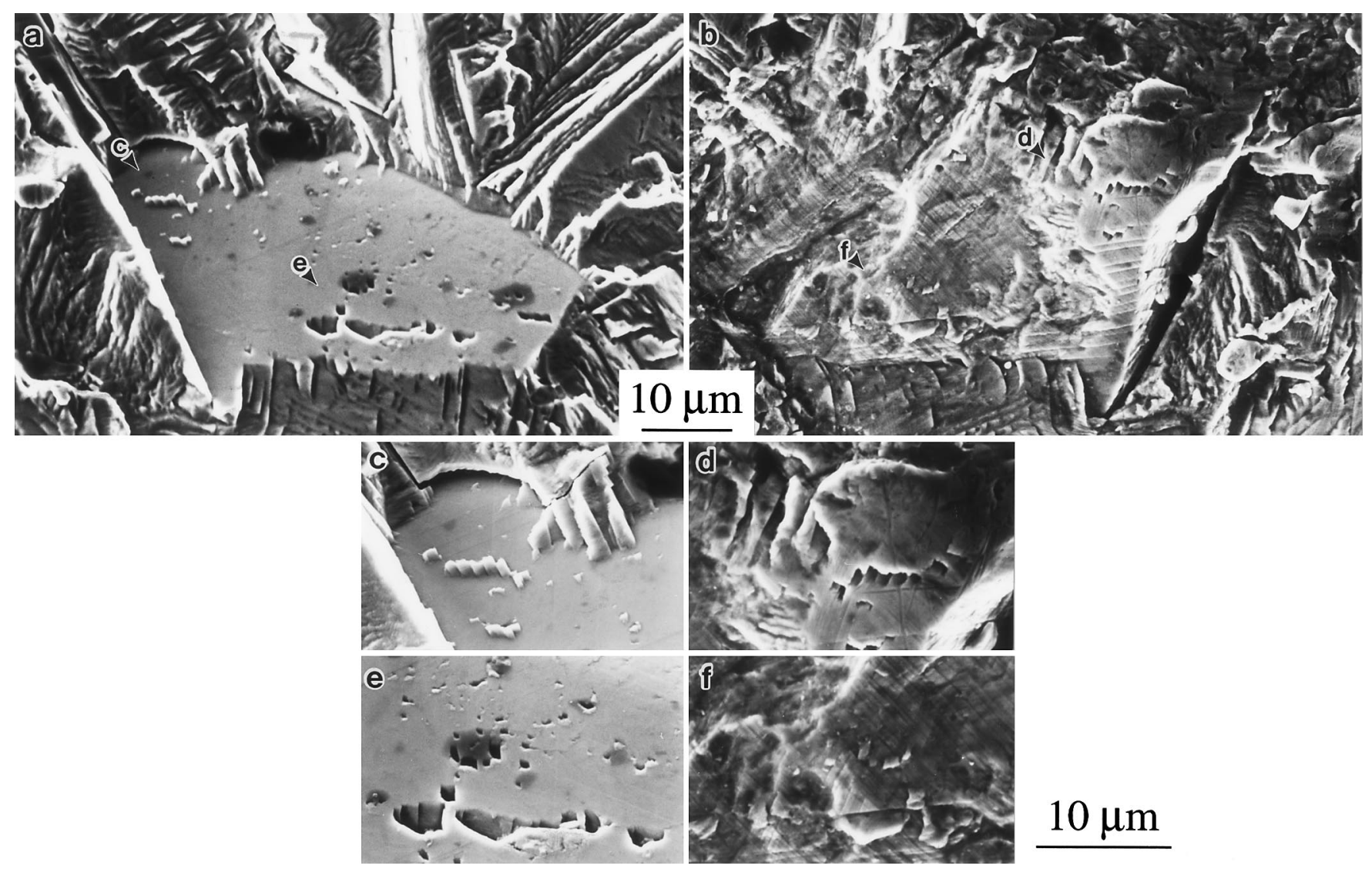

Fig. 9-(a) through $(f)$ SEM matching-halves photographs of an initiation site of $24 \mathrm{Cr}-15 \mathrm{Ni}$ steel, which failed with $\sigma_{\max }=1037 \mathrm{MPa}$ at $4 \mathrm{~K}$. Photographs (c) and (e) are the magnified images of protrusions and intrusions on the facet in photograph (a). Photographs (d) and (f) are the magnified images of photograph (b) and show the intrusions and protrusions on the matching surface.

The area of the initiation site in $24 \mathrm{Cr}-15 \mathrm{Ni}$ steel became large in the lower-peak stress or longer-life range. At lower stress levels, the subsurface crack initiation sites consist of facets with evidences of microcrack growth, as shown in Figures 8 and 12 .

Figure 13 shows the dependence of the subsurface crack size $\left(f_{s}\right)$ on the peak cyclic stress for the both steels. For $24 \mathrm{Cr}-15 \mathrm{Ni}$ steel, the $f_{s}$ sharply increases from about 10 to $110 \mu \mathrm{m}$ regardless of testing temperature, as the peak cyclic stress decreases. For $32 \mathrm{Mn}-7 \mathrm{Cr}$ steel, most of the data plots are in the band region in Figure 13, although data plots are scattered and the number of them is small. Both steels basically show that the peak stress is lowered with the increasing size of the subsurface crack initiation site. Namely, specimens with a large subsurface crack failed at lower stress levels.

No significant feature in chemistry was detected at the subsurface crack initiation sites; namely, energy-dispersive spectroscopy (EDS) analysis did not show any difference in $\mathrm{Fe}, \mathrm{Mn}$, and $\mathrm{Cr}$ concentrations between the matrix and the initiation sites. Grain boundary segregation of $\mathrm{C}, \mathrm{B}, \mathrm{N}$, etc., could not be determined using EDS.

\section{Deformation Structure}

For the $24 \mathrm{Cr}-15 \mathrm{Ni}$ steel, parallel straight bands are observed in the planar dislocation structures at the highest maximum stress level where surface crack initiation oc- curred, as shown in Figure 14. They are $\{111\}$ slip bands that group closely spaced dislocations and are distributed over a grain. The dominant deformation mode is the (111)$\langle 110\rangle$ slip system, and the cross-slip of dislocations is strongly suppressed. The secondary (conjugate) slip is also operative. The interaction between primary slip bands and secondary ones, where steps or knots are formed, can be seen. The dislocation movements are restricted on their slip planes. In addition, some (111) stacking faults were observed, as shown in Figure 14(a), although the deformation twinning and $\varepsilon$-martensite were not identified.

At the higher stress level where subsurface crack initiation occurred, the dislocation density is less and the plastic deformation is more distinctly localized, as shown in Figure 15(a). The dislocation arrangement is developed mainly by pileups or coplanar arrays. Although the distinct slip bands are not numerous, microslip bands are widely spaced, as opposed to those at an even higher stress level, as shown in Figure 16. The appearance of secondary slip and (111) stacking faults are often observed in the region. Neither deformation twinning, kink, nor $\varepsilon$-martensite was observed. The slip system is also predominantly (111)- $\langle 110\rangle$. The cross-slip of dislocations is strongly suppressed, and dislocation movements are restricted to their slip planes. The dislocation arrays are piled up and blocked at the grain boundary, as shown in Figures 15(b) and (c). Closer to the grain boundary, the spacing between neighboring dislocations in the array becomes gradually smaller, and the local 

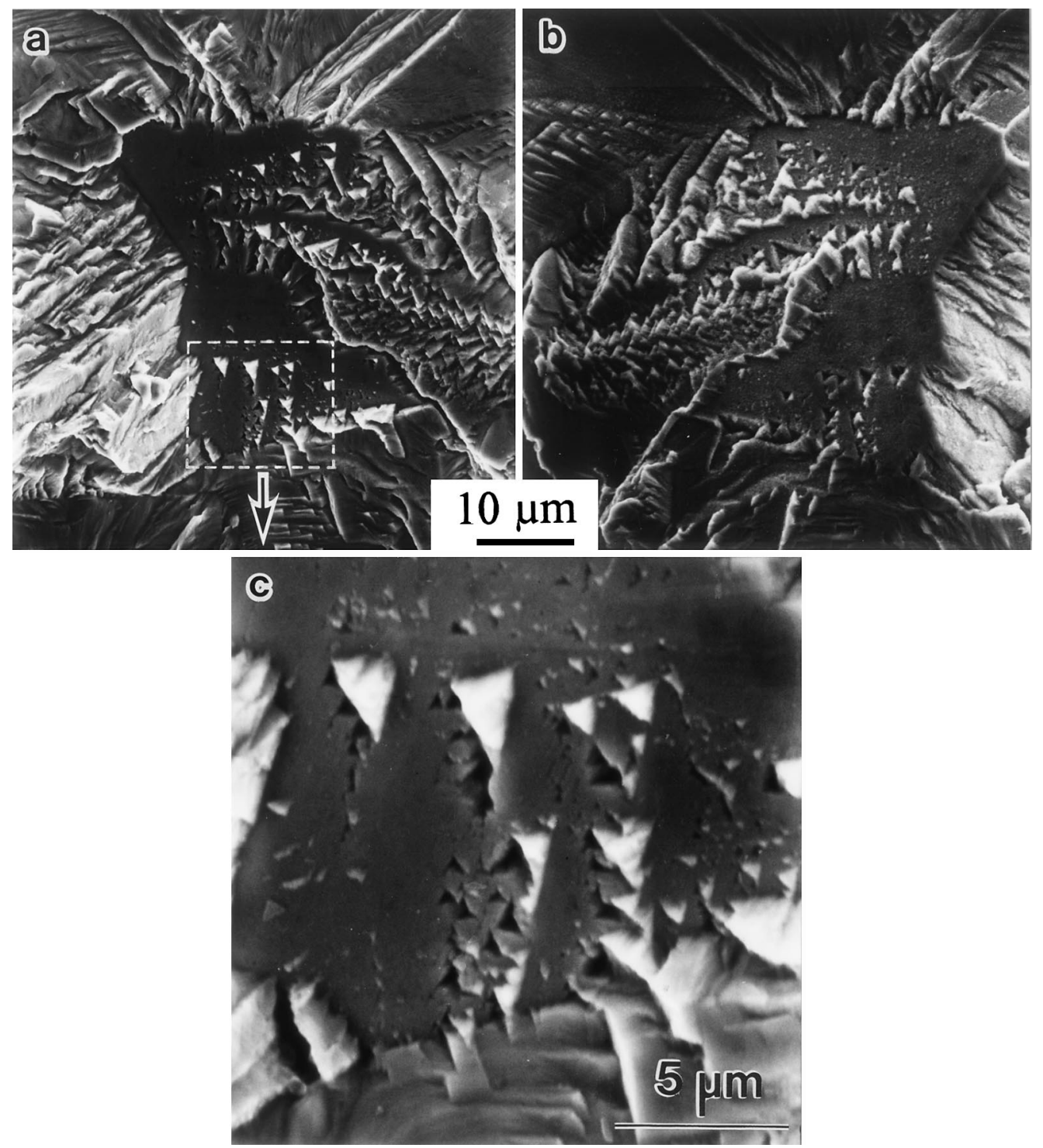

Fig. 10-(a) through (c) SEM matching-halves photographs of an initiation site of 32Mn-7Cr steel, which failed with $\sigma_{\max }=1134 \mathrm{MPa}$ at $4 \mathrm{~K}$. Photograph (c) is the magnified image of triangular pits in photograph (a).

distortion of crystal occurs in the vicinity of the grain boundary. Dark-field micrographs, in Figures 15(d) and (e), show the strain concentration or grade at a grain boundary where two dislocation systems (A and B in (d) and C and $\mathrm{D}$ in (e)) intersect. The grain boundary in Figure 15(b) is identified as a $\Sigma=3$ twin boundary, and slip system B transfers into the adjoining grain.

The dislocation configurations observed in the specimen cycled at the lower stress level were mainly dislocation pileups near grain boundaries in both steels, as shown in Figure 17. Dislocations had generated in more than one slip system at the stress level of $\sigma_{a}=161 \mathrm{MPa}$, while their density was rather low. Figure 17 shows micrographs taken, with different diffraction conditions, of the piled-up dislocations A and B intersecting a grain boundary. The lattice dislocations in slip systems A and B are absorbed by the grain boundary and become grain boundary dislocations.

For the $32 \mathrm{Mn}-7 \mathrm{Cr}$ steel, the dominant deformation mode was also the $\{111\}-\langle 110\rangle$ slip system, and the dislocation motion was planar. Deformation twinning and $\varepsilon$-martensite were not a major factor in cyclic deformation, and no stack- ing faults were detected, either. At the higher stress level, mainly slip bands were observed. At the lower stress level, microslip or dislocation pileups were blocked or sharply localized at grain boundaries. The dislocation (slip deformation) structure of $32 \mathrm{Mn}-7 \mathrm{Cr}$ steel was almost the same with that of $24 \mathrm{Cr}-15 \mathrm{Ni}$ steel. The plastic deformation in those steels was highly inhomogeneous, and the coplanar dislocation pileups produced the localized deformation and/or strain concentration at a grain boundary.

\section{DISCUSSION}

\section{A. Grain Boundaries as Barriers to the Glide and/or as Sources of Lattice Dislocation}

Microscopically, low-temperature deformation of polycrystalline metals proceeds by dislocation movement within individual grains and across the boundaries between neighboring grains. Grain boundaries allow slip propagation from one grain to another by several modes. Among them are absorption of dislocations into the grain boundary, ab- 

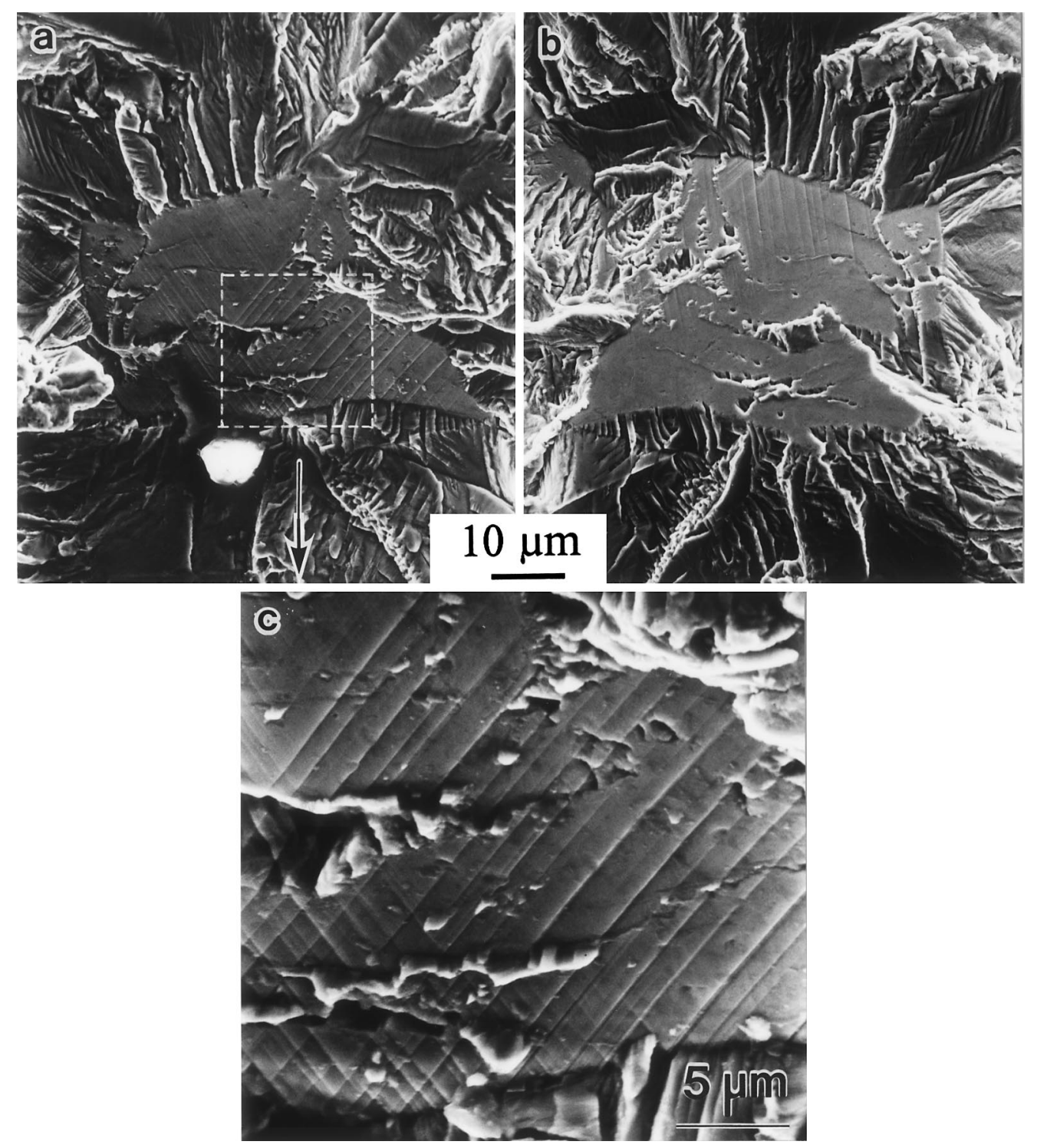

Fig. 11-(a) through (c) SEM matching-halves photographs of an initiation site of 32Mn-7Cr steel, which failed with $\sigma_{\max }=1204 \mathrm{MPa}$ at $4 \mathrm{~K}$. Photograph (c) is the magnified image of slip line traces in photograph (a).

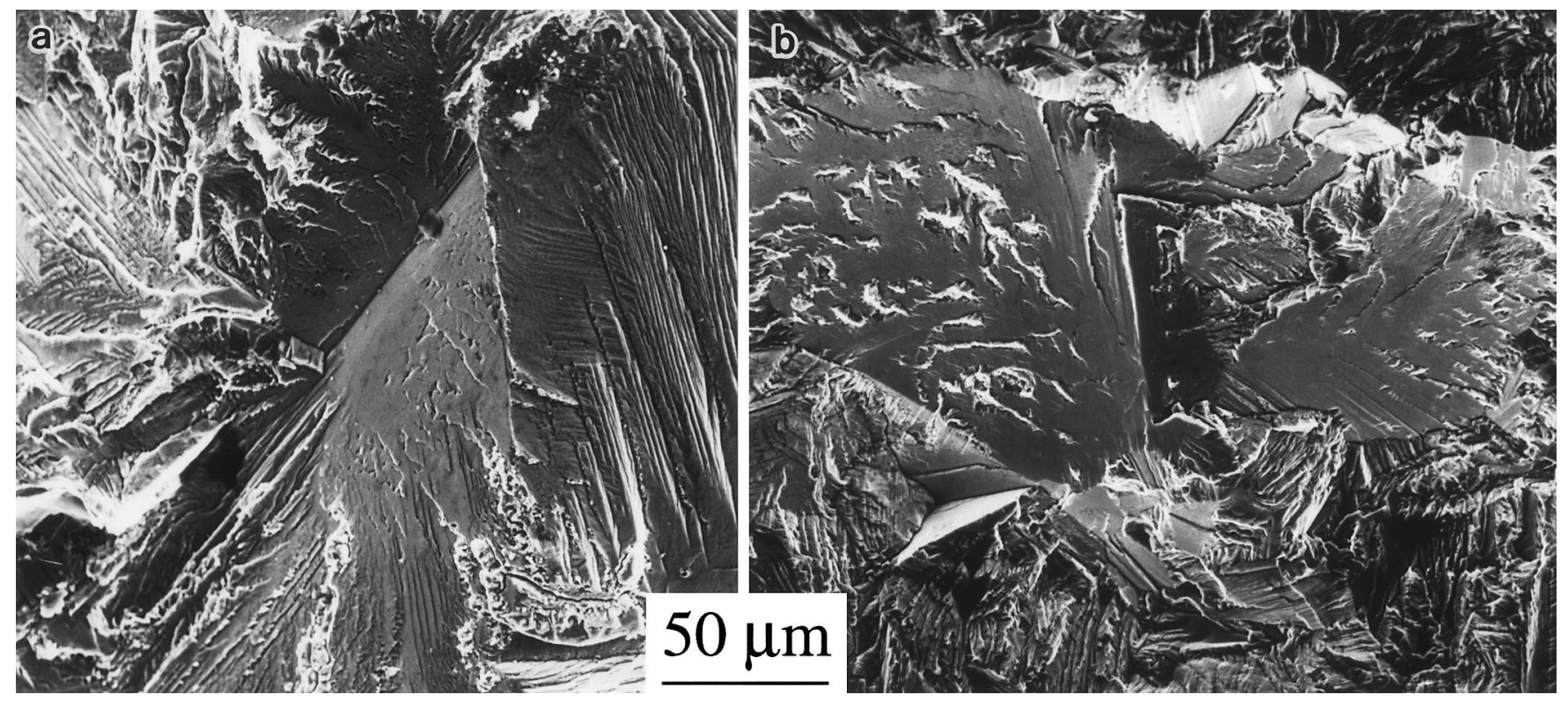

Fig. 12-SEM photographs of an initiation site of $24 \mathrm{Cr}-15 \mathrm{Ni}$ steel, which (a) failed with $\sigma_{\max }=691 \mathrm{MPa}$ at $77 \mathrm{~K}$ and $(b)$ failed with $\sigma_{\max }=395 \mathrm{MPa}$ at $293 \mathrm{~K}$. 


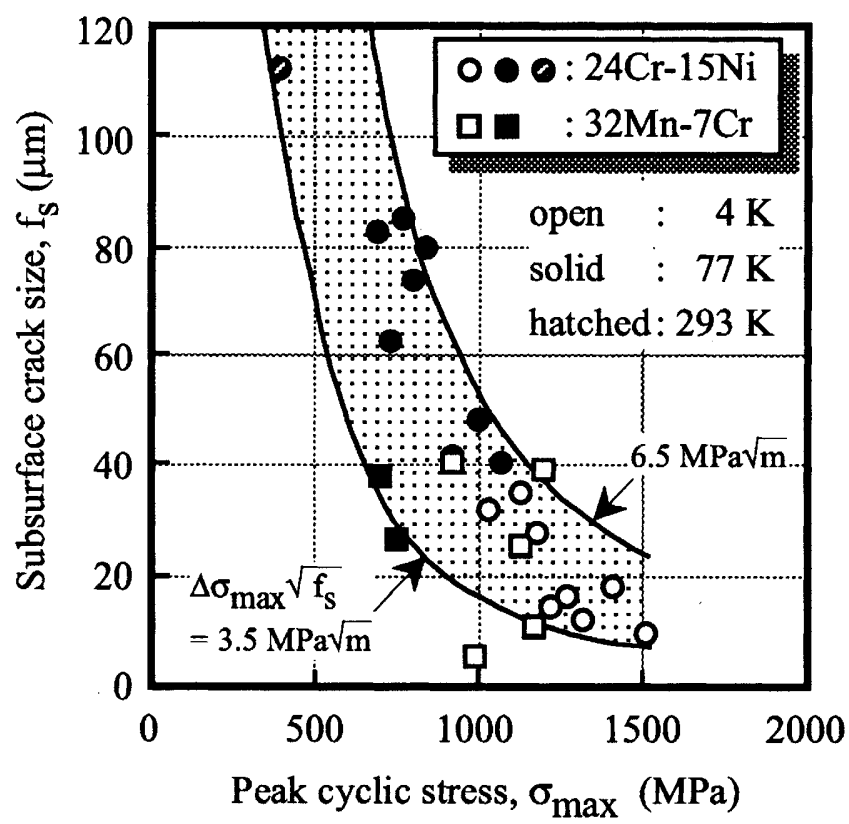

Fig. 13-Relationship between subsurface crack size, $f_{s}$, and peak cyclic stress for the steels.

sorption and emission, and absorption-emission-reflection. Grain boundaries are, therefore, expected to play an important role in controlling the mechanical properties of the materials. ${ }^{[17,18]}$ Both TEM dynamic and static deformation studies have been done on the interaction of lattice dislocations with grain boundaries in austenitic stainless steels. ${ }^{[19,20,21]}$ Most of the results were $\Sigma=3$-type grain boundaries, because such boundaries are frequently observed. ${ }^{[21]}$ For the present steels, the number of $\Sigma=3$ twin boundaries (red color) in the field of view of orientation imaging microscopy was also dominant, as shown in Figure 18. Transmission of a dislocation through a grain boundary requires that (1) the slip plane of the piled-up dislocations and the slip plane of the transmitted dislocations must have a common line of intersection in the grain boundary plane, and (2) the Burgers vector of the piled-up dislocations and the transmitted dislocations must be equal to and colinear with the line of intersection; it is termed the direct transfer. ${ }^{[19]}$ These conditions can be satisfied for properly oriented screw dislocations intersecting a twin boundary, i.e., $\Sigma=3$. In general, the stresses needed for dislocation transmission are higher than the macroscopic yield stress. ${ }^{[21]}$ Therefore, the direct transfer is believed to be a limited case. Under other conditions, $\Sigma=3$ boundaries can play an important role as barriers to the glide of lattice dislocations.

As shown in Figure 16, slip bands were observed at the higher stress level. Figure 19 presents the interaction of slip bands with a grain boundary which was identified as a $\Sigma$ $=3$. Slip bands in grain 1 might impinge at the grain boundary and emit dislocations and slip bands into grain 2 . The observation of slip bands is in agreement with the presence of line traces, pits, and protrusions on the intergranular facets, such as in Figures 9 through 11.

In another case, piled-up dislocations impinged on a grain boundary, as shown in Figures 15 and 17. In Figure 20, the piled-up screw dislocations on slip system A in grain 1 have a Burgers vector of $\mathbf{a} / 2[101]$ and transfer
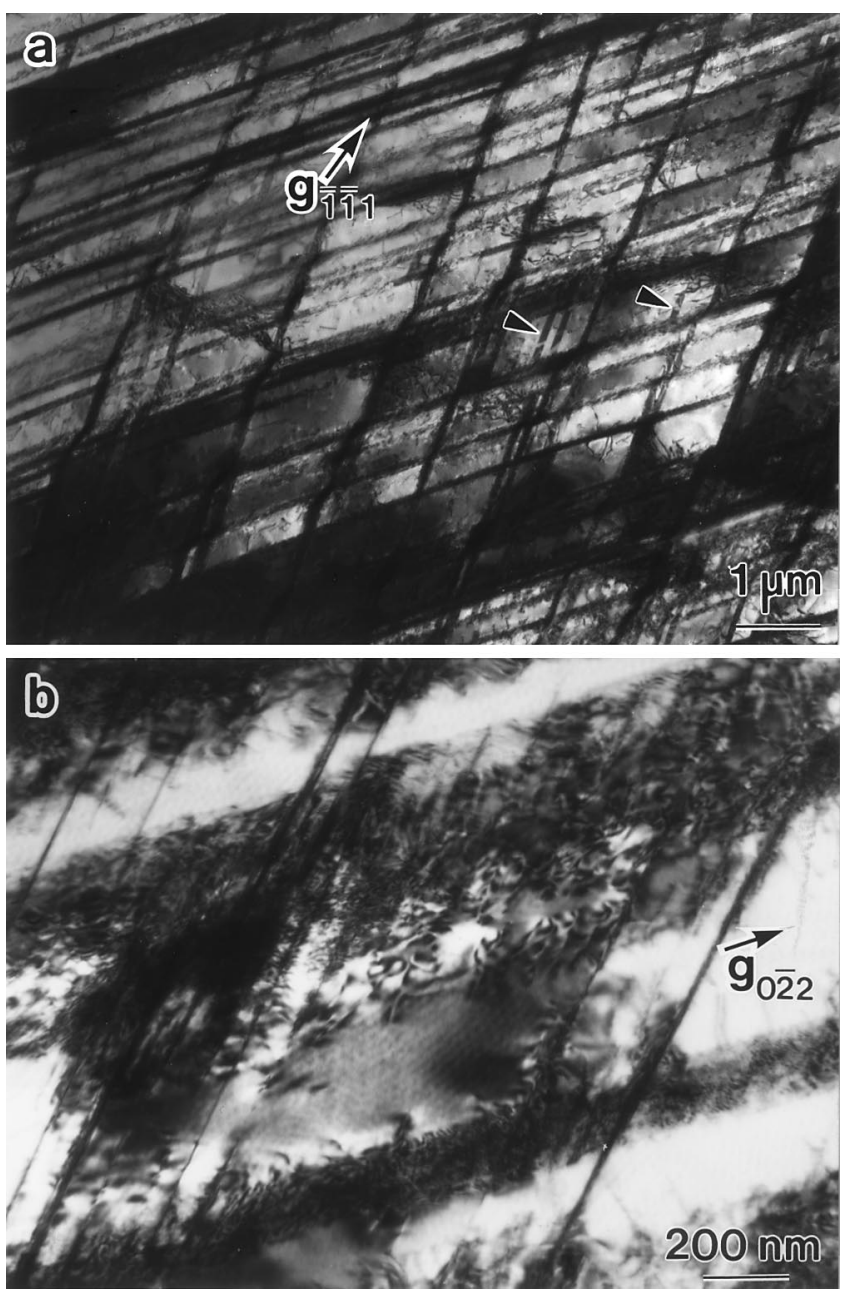

Fig. 14-Deformation structure of a cyclically deformed $24 \mathrm{Cr}-15 \mathrm{Ni}$ sample after 59,570 cycles at $4 \mathrm{~K}$ with stress amplitude, $\sigma_{a}=838 \mathrm{MPa}$ (surface crack initiation): (a) beam direction is near [112], and $(b)$ beam direction is near [011]. The arrows in photograph (a) indicate stacking faults.

through a grain boundary in which residual grain boundary dislocations are created. The grain boundary was analyzed as a $\Sigma=3$ twin boundary. Closer to the grain boundary, the spacing between dislocations in arrays of the incoming system labeled A is narrower, as shown in Figures 15(b) and 17. The stress or strain concentration at the grain boundary might be the source of the emission of dislocations in the adjacent grain 2. If the slip planes of the incoming system A and the emerging system B have a common line of intersection in the grain boundary, the Burgers vectors of the dislocations are not collinear, nor are their line directions parallel to the intersection line. In this situation, therefore, the geometric conditions required for direct transfer are not satisfied. The glissile grain boundary dislocations might pile up at the boundary step, indicated by the arrow at system L.

As shown in Figures 15, 16(a), 17, and 20, strain was accumulated in the vicinity of a grain boundary due to the glide of lattice dislocations. Especially, it arose from slip on secondary systems operating near the grain boundary at a lower stress amplitude, as shown in Figure 17. It is considered that the dislocation interactions with grain boundaries result in microcrack nucleation along the boundary or 

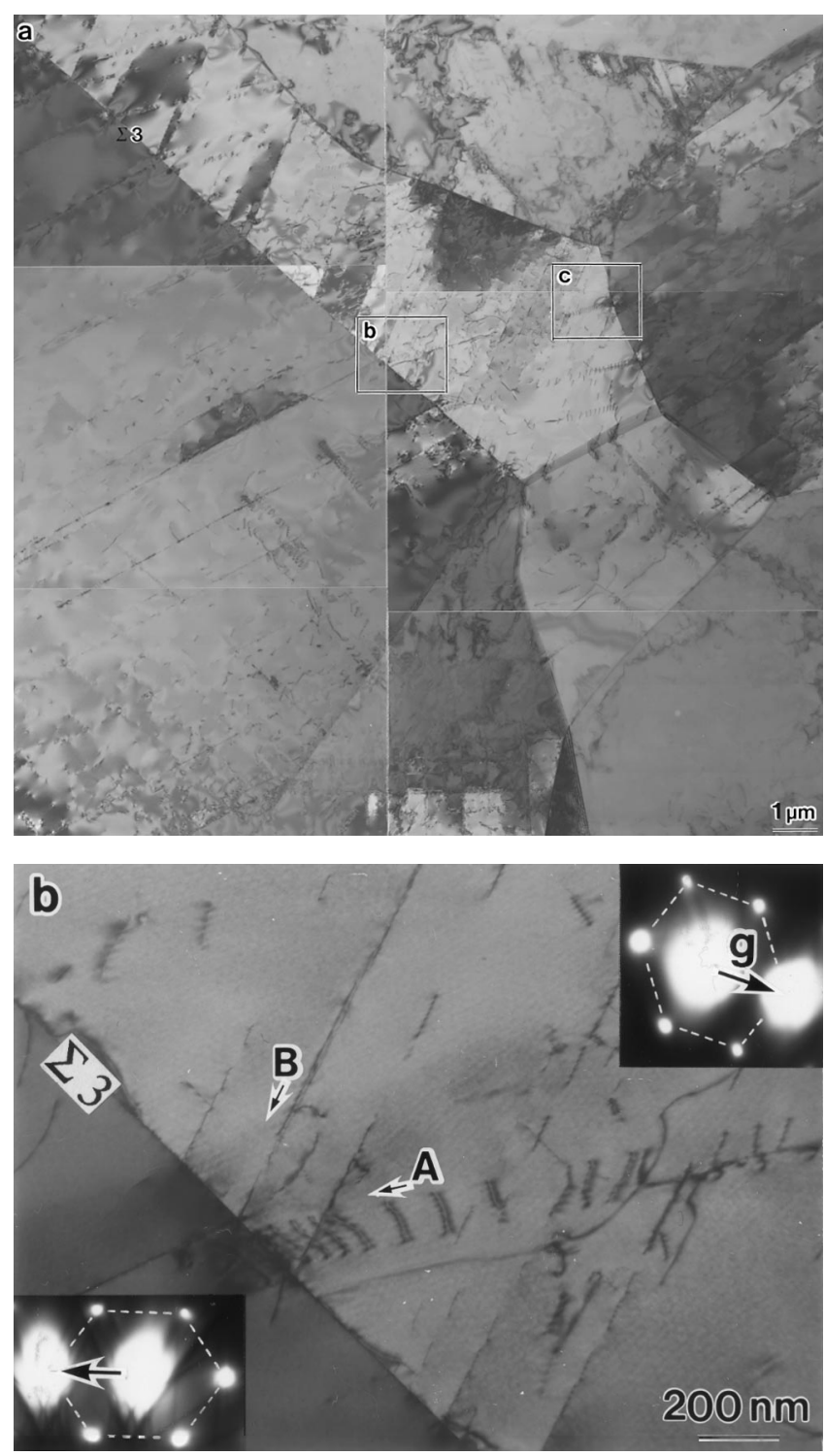

Fig. 15- (a) through (e) Dislocation structures of a cyclically deformed $24 \mathrm{Cr}-15 \mathrm{Ni}$ sample after 127,360 cycles at $4 \mathrm{~K}\left(\sigma_{a}=636 \mathrm{MPa}\right)$. Photographs (b) and (c) are the magnified images of pileups in (a). Photographs (d) and (e) are the dark-filed images with $-2 \mathrm{~g}$ condition of photographs (b) and (c), respectively.

dislocation generation in the adjoining grain to relieve the accumulated strain in the grain boundary.

\section{B. Intergranular Cracking in the Austenitic Steels Containing Manganese}

Intergranular fracture has been frequently observed at low temperatures in high-Mn austenitic steels, being associated with the ductile-brittle transition. ${ }^{[22]}$ However, the true reason of intergranular fracture in high-Mn austenitic steels is still unclear. Tomota and Shibuki ${ }^{[23]}$ and Tanaka et $a l .{ }^{[24]}$ summarized the main ideas concerning embrittlement
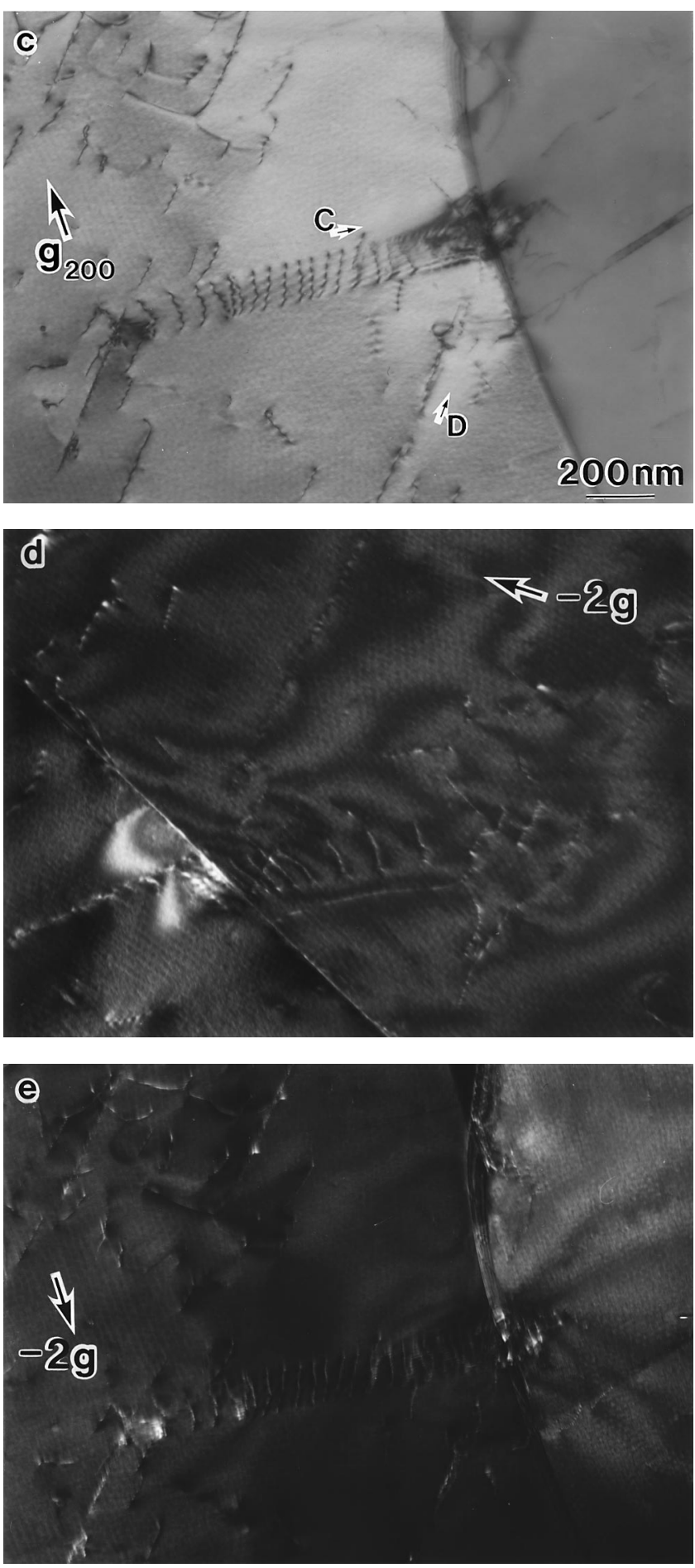

of the steels. Tomota et al. ${ }^{[23]}$ noted that the grain boundary strength of Fe-Mn binary austenitic alloys is intrinsically low, and that the intergranular fracture in low-temperature tensile tests is suppressed by grain refining.

For the steels under consideration, no intergranular cracking was detected in both tensile and toughness tests, even at $4 \mathrm{~K}$, and the fracture mode was fully ductile. In the case of $32 \mathrm{Mn}-7 \mathrm{Cr}$ steel, however, crystallographic facets were observed in the lower- $\Delta K$ region of the crack propagation plane (stage II) for samples fractured at $4 \mathrm{~K}$, as shown in Figure 21. (a) Point defects or (b) line protrusions that develop into fissured glide bands are revealed on the 

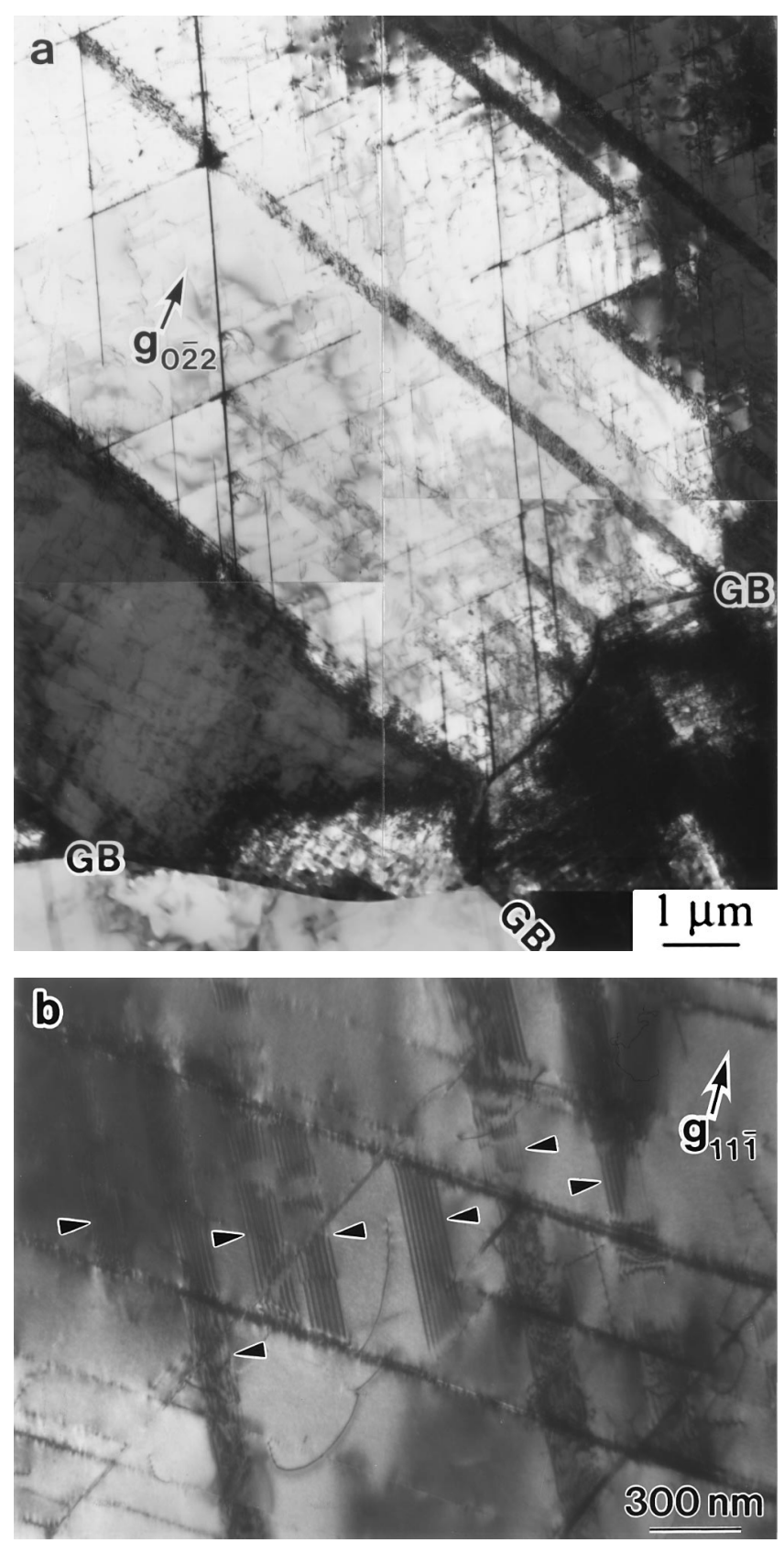

Fig. 16- (a) and (b) Deformation structures of a cyclically deformed $24 \mathrm{Cr}-15 \mathrm{Ni}$ sample after $1,391,710$ cycles at $4 \mathrm{~K}\left(\sigma_{a}=513 \mathrm{MPa}\right)$.

facets. These features were observed on the fatigue fracture surface of a high-strength alloy which exhibited low plasticity and planar slip deformation. ${ }^{[25]}$

On the other hand, the concentration of $\mathrm{Mn}$ in $24 \mathrm{Cr}-15 \mathrm{Ni}$ steel is not so high, but it might be enough for its effect on the embrittlement of grain boundaries. In fact, $25 \mathrm{Cr}$ $13 \mathrm{Ni}$ steel, which has almost the same composition as $24 \mathrm{Cr}-15 \mathrm{Ni}$ and no $\mathrm{Mn}$ addition, hardly exhibits intergranular fatigue cracking. ${ }^{[26]}$ Therefore, the embrittlement of the steel containing $\mathrm{Mn}$ is also related to the intergranular cracking of the tested steels. It means that the steel containing Mn provides a weak link in the grain boundary against strain incompatibility and microcrack generation, although the reason of grain boundary embrittlement is not clear.
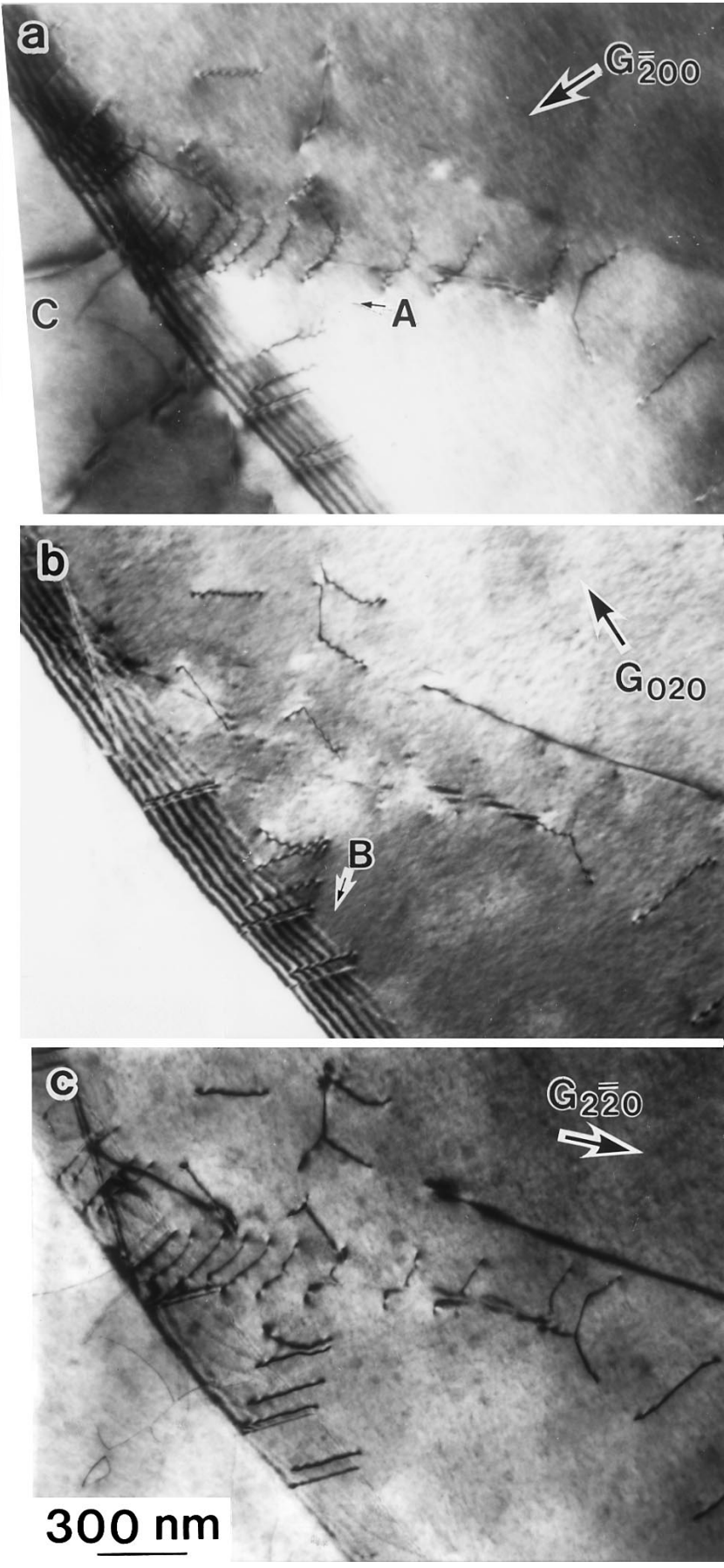

Fig. 17- (a) through $(c)$ Dislocation structures of a cyclically deformed $32 \mathrm{Mn}-7 \mathrm{Cr}$ sample after $1,590,000$ cycles at $293 \mathrm{~K}\left(\sigma_{a}=161 \mathrm{MPa}\right)$. Lattice pileups involving two incoming systems (A and B) produced by absorption into the grain boundary and emission of a lattice dislocation C. The arrows in photograph (b) indicate stacking faults.

\section{Dependence of Subsurface Crack Size on Stress Range}

Kitagawa et al. ${ }^{[27]}$ reported that the fatigue limit of a material containing a pre-existing defect in the specimen surface can be determined from the relationship between the defect size and the threshold stress range. In the range of $2 a$ (crack length) $>d_{c}$ (threshold defect size), where the small defect such as an inclusion is equivalent to a microcrack, the $\Delta K_{t h}$ value determines the fatigue limit threshold stress range.

In our previous article, ${ }^{[5]}$ we discussed the dependence of 

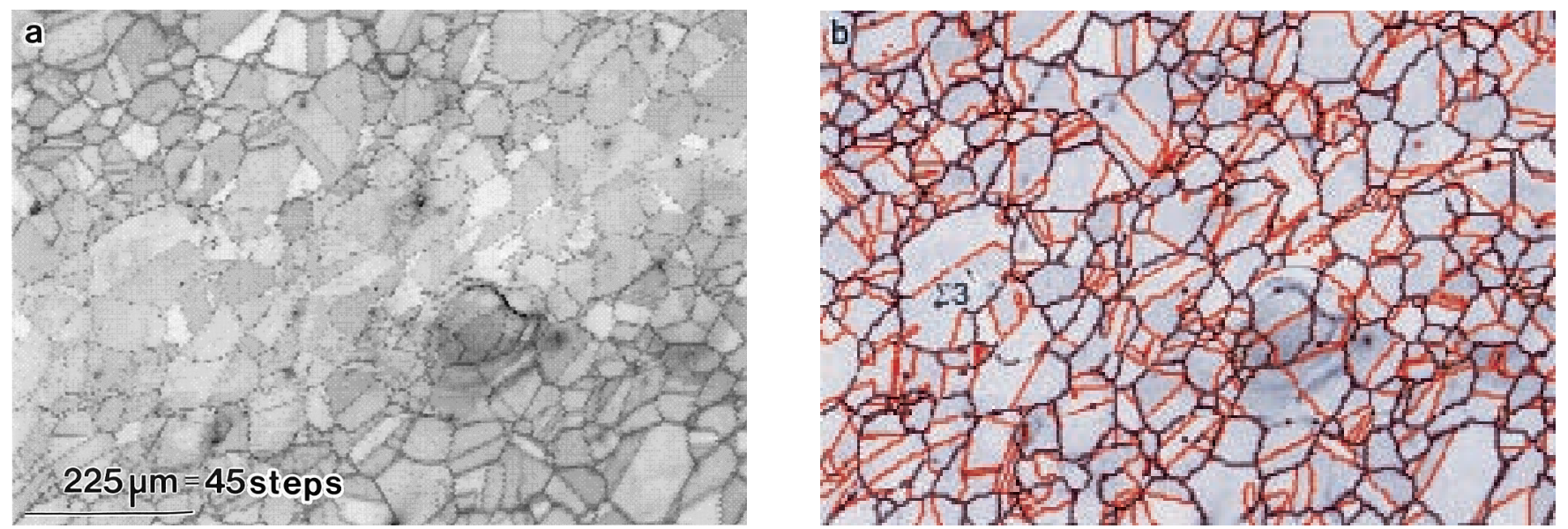

Fig. 18- (a) An orientation imaging microscopy image in the TD plane section of 32Mn-7Cr steel and (b) the result of its boundary analyses. The red lines are $\Sigma=3$ boundary, and the black lines are other large angle boundaries (higher than $15 \mathrm{deg}$ ).

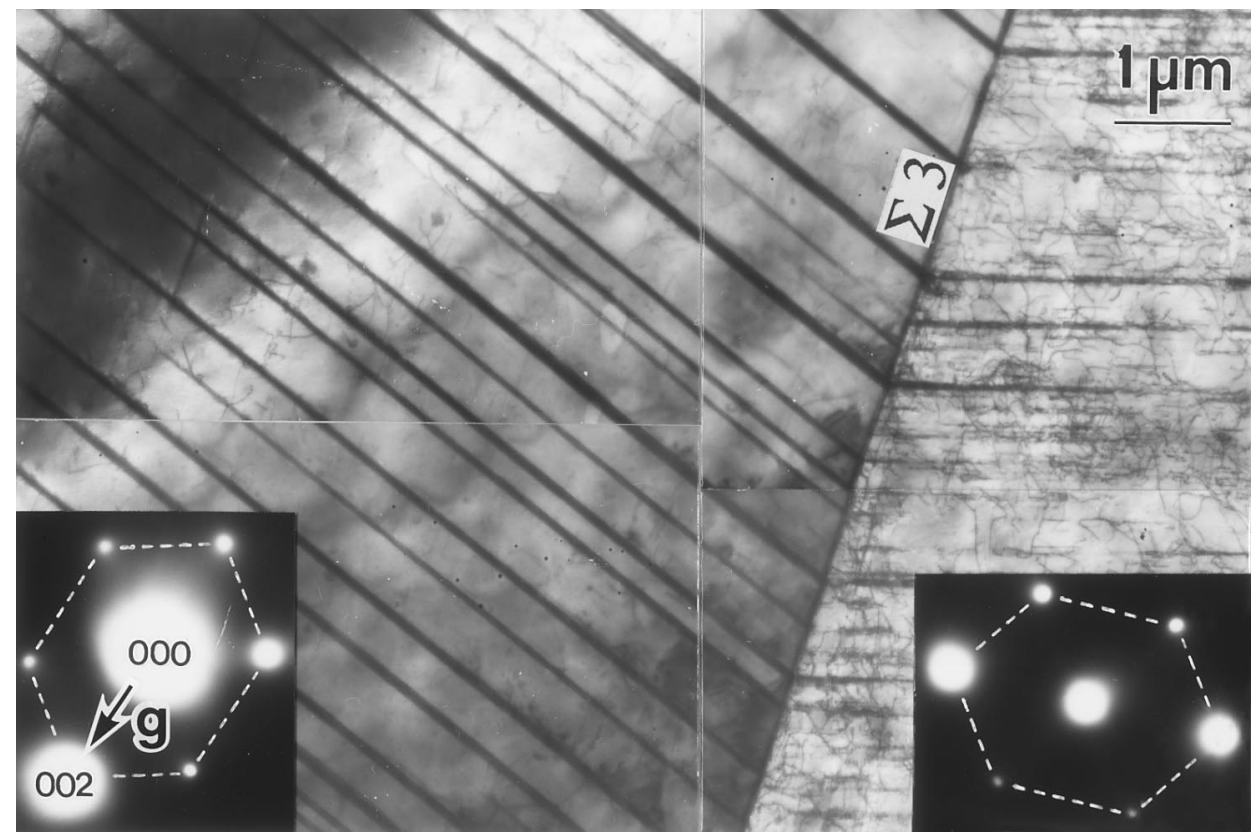

Fig. 19-Deformation structure of a cyclically deformed 32Mn-7Cr sample after 174,200 cycles at $4 \mathrm{~K}\left(\sigma_{a}=612 \mathrm{MPa}\right)$.

subsurface crack size on stress range for Ti-6Al-4V alloys, and modified the previous relation and introduced the idea of microcrack growth. It was reasonable to explain the experimental results. In fact, the microcrack nucleated in an $\alpha$ grain did not always provide a critical main crack size and grew until it finally formed the initiation site. Then, we proposed that a microcracking and its growth generated a subsurface crack initiation site and that the " $\Delta K_{I \max }=$ constant" relationship to the subsurface crack size basically controlled the transition from stage I to stage II.

By introducing these ideas, we evaluate the critical condition that a microcrack becomes a fatal crack, in a given stress range, for the present steels as well as for Ti-6Al-4V alloys. The following assumptions are also made for simplifying the analysis of the threshold condition: (1) the parameter $f_{s}$ represents the crack length of subsurface crack initiation site, while the initiation site has a complicated three-dimensional shape; (2) the subsurface crack initiation site was formed through microcracking and its growth; and (3) the stress at the subsurface crack tip, given the critical size $f_{s}$, is equal to the principal stress under mode I, although the local stress concentration which produced a microcracking is superimposed on the principal stress at the crack-tip field. Then, an approximate equation to give the maximum stress intensity range $\left(\Delta K_{I \max }\right)$ at the subsurface crack tip is represented as follows:

$$
\begin{aligned}
\Delta K_{I \max } & =A \cdot \Delta \sigma_{\max } \sqrt{\pi f_{s}} \\
\Delta \sigma_{\max } & =\sigma_{\max }-\sigma_{\min }
\end{aligned}
$$

where $A$ is the stress intensity coefficient and $\Delta \sigma_{\max }$ is the maximum cyclic stress range. The coefficient $A$ depends on the shape and location of the initiation site. On the basis of Eq. [1], Figure 22 rearranges the data in Figure 13 and shows the relationship between $\Delta \sigma_{\max }$ and $\Delta \sigma_{\max } \sqrt{f_{s}}$. The value of $\Delta \sigma_{\max } \sqrt{f_{s}}$ for both steels is mostly in a range be- 


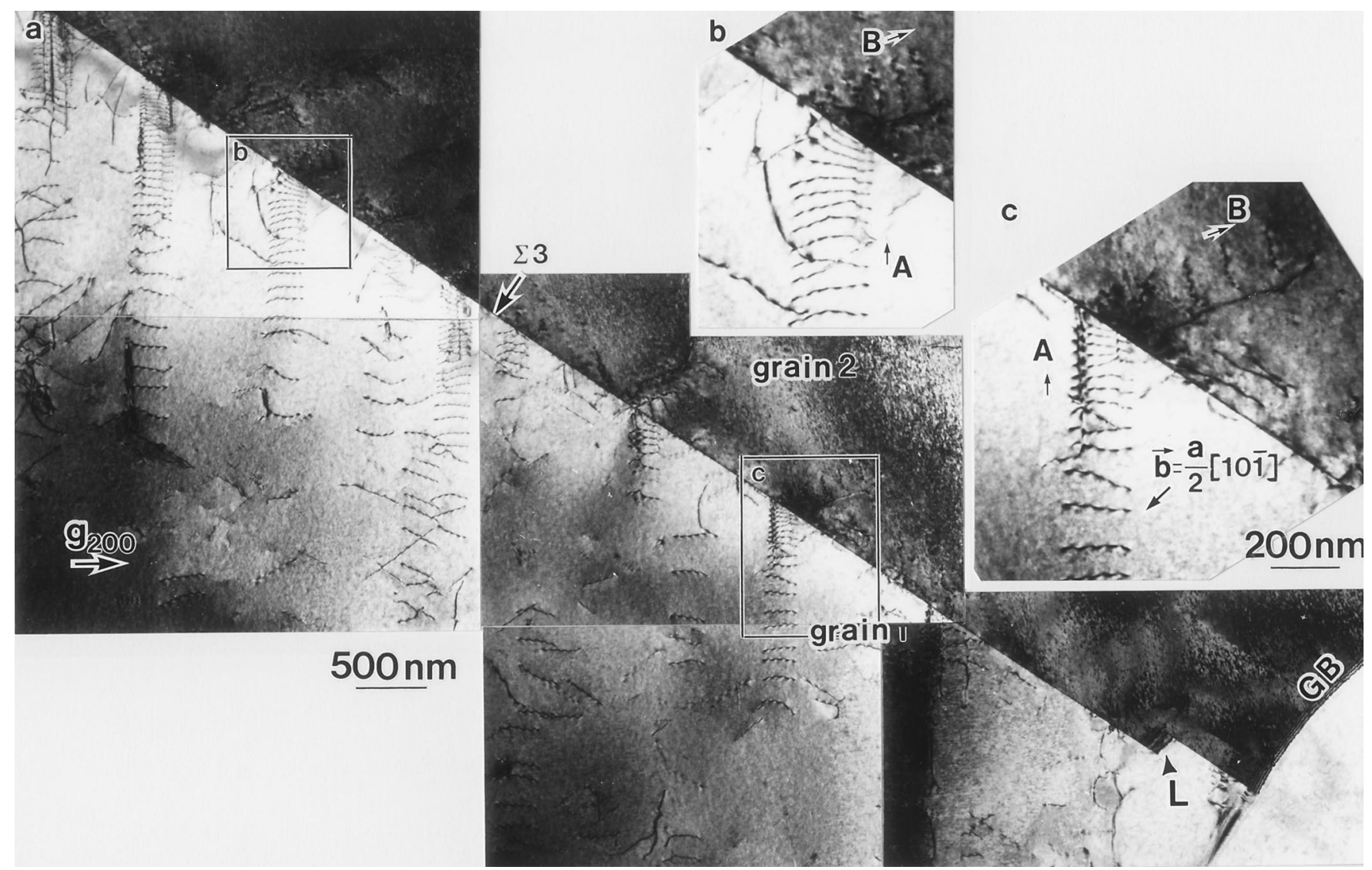

Fig. 20- (a) through $(c)$ Dislocation pileups of a cyclically deformed 32Mn-7Cr sample after 3,769,180 cycles at $77 \mathrm{~K}\left(\sigma_{a}=342 \mathrm{MPa}\right)$. Photographs (b) and (c) are the magnified image of pileups in photograph (a). Slip transfer through a $\Sigma=3$ twin boundary: the incident slip system is designated A, and the emerging system is B. L in photograph (a) indicates the boundary step.
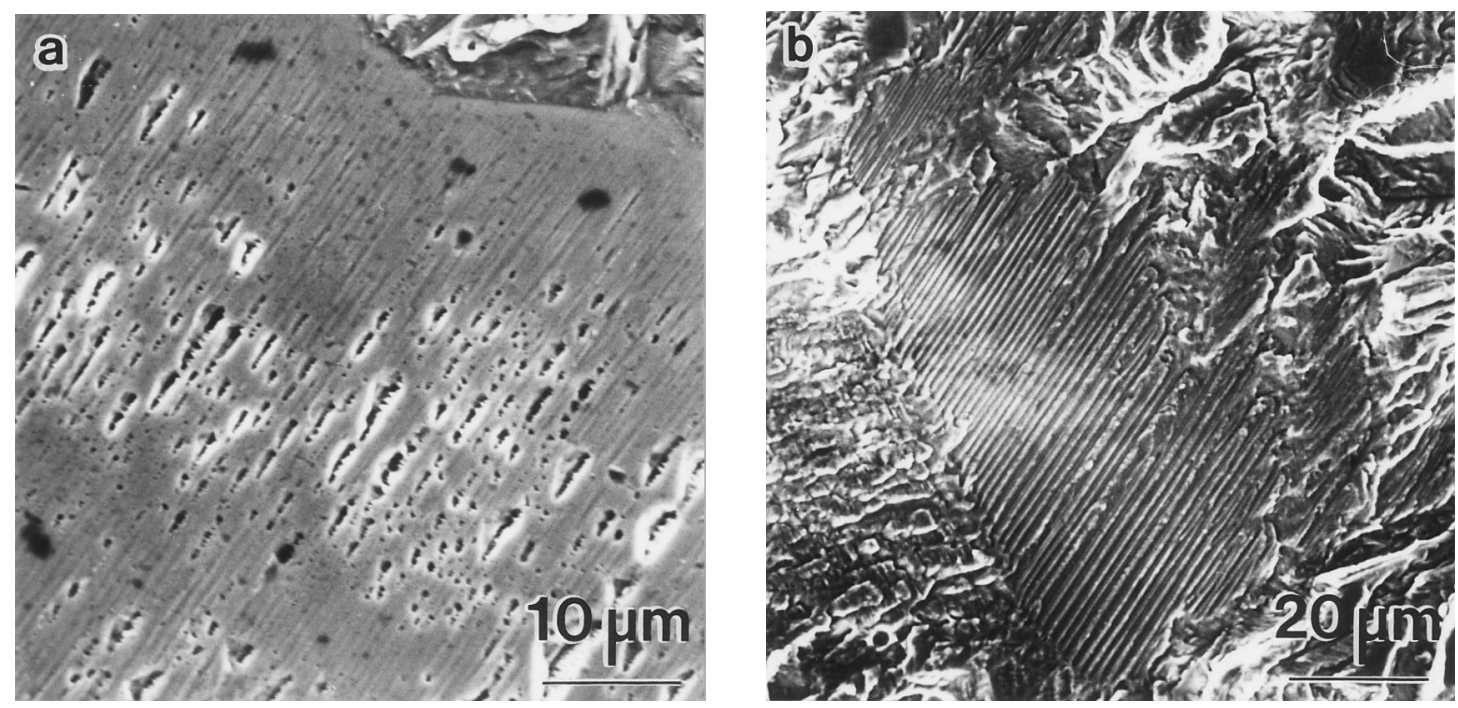

Fig. 21-Point ruptures in (a) slip bands and $(b)$ line markings on the facet in the fatigue crack propagating plane (low $\Delta K$ stage II region) of fractured $32 \mathrm{Mn}-7 \mathrm{Cr}$ samples at $4 \mathrm{~K}:(a) \sigma_{\max }=992 \mathrm{MPa}$ and $(b) \sigma_{\max }=921 \mathrm{MPa}$.

tween 3.5 and $6.5 \mathrm{MPa} \sqrt{\mathrm{m}}$. When the curves of $\Delta \sigma_{\max } \sqrt{f_{s}}$ $=3.5$ and $6.5 \mathrm{MPa} \sqrt{\mathrm{m}}$ are overlaid in Figure 13, it is confirmed that almost all the data are included between the curves. The bigger $\Delta \sigma_{\max } \sqrt{f_{s}}$ data are considered to exhibit the excess of the subsurface crack initiation site size from a threshold value, because the $f_{s}$ value depends on the grainsize unit. It is also difficult to measure the value of $f_{s}$ precisely. Then, the scatter of $\Delta \sigma_{\max } \sqrt{f_{s}}$ in Figure 22 may be reasonable. Hence, there might be a threshold condition, $\Delta K_{\text {Imax }}=$ constant, at any stress level where subsurface 


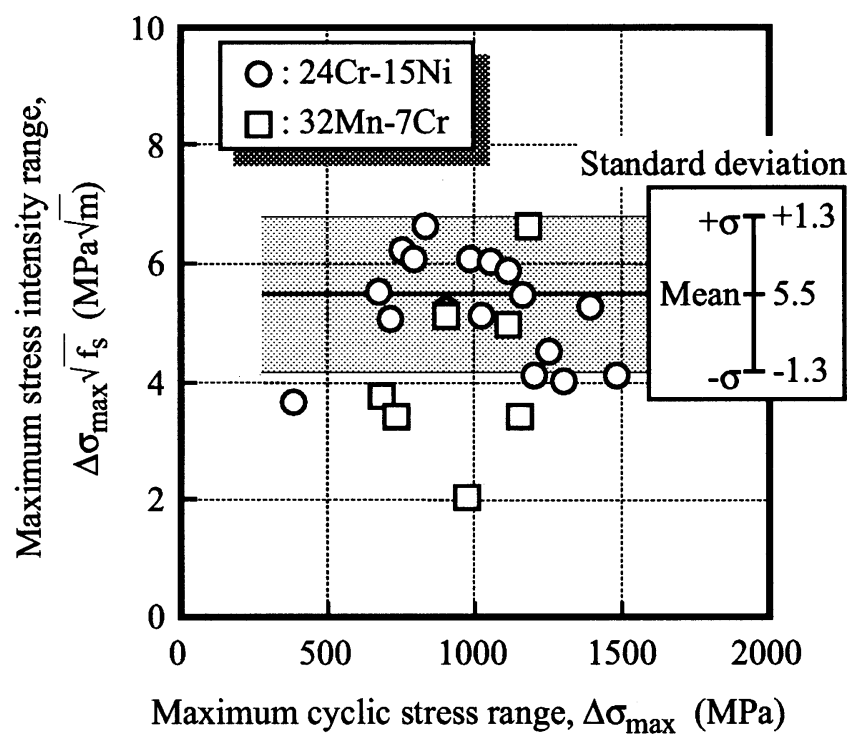

Fig. 22-Relationship between maximum stress intensity range, $\Delta \sigma_{\max } \sqrt{f_{s}}$, and maximum cyclic stress range, $\Delta \sigma_{\max }$, for the subsurface fractured samples.

crack initiation occurs. It is suggested that the main crack (stage II) starts to propagate at any stress level when the local stress intensity factor range reaches over a constant around the subsurface crack (stage I).

\section{CONCLUSIONS}

The high-cycle fatigue generation and subsurface crack initiation of the high-strength austenitic steels, i.e., 24Cr$15 \mathrm{Ni}$ and $32 \mathrm{Mn}-7 \mathrm{Cr}$, at low temperatures were investigated. The results are as follows.

1. Subsurface crack initiation was detected in the lowerpeak stress and/or in the longer-life range, especially at 4 and $77 \mathrm{~K}$. The subsurface crack initiation site in $24 \mathrm{Cr}-$ $15 \mathrm{Ni}$ and $32 \mathrm{Mn}-7 \mathrm{Cr}$ steels was identified as an intergranular facet or facets, respectively. The location of the sites was scattered, from in the vicinity of the specimen surface to the center of the specimen, for both steels.

2. For $24 \mathrm{Cr}-15 \mathrm{Ni}$ steel, the peak stress is clearly lowered with the increasing size of the subsurface crack initiation site. Namely, specimens with a large subsurface crack failed at lower stress levels.

3. At the higher maximum stress level, subsurface crack initiation sites clearly displayed pits, protrusions, and line traces on the intergranular facets. Coplanar slip on the (111)- $\langle 110\rangle$ system occurred predominantly, and dislocation movements were restricted to their slip planes. Microslip bands interacted with a grain boundary.

4. At the lower maximum stress level, piled-up dislocations impinged on a grain boundary and also interacted with a grain boundary.

5. The localized deformation and/or strain concentration by dislocation pileups or arrays was considered to be a potential source of grain boundary cracking in a specific incompatibility of the grain boundary.

\section{REFERENCES}

1. K. Nagai, T. Yuri, O. Umezawa, T. Ogata, and K. Ishikawa: Stainless Steel '91, Iron and Steel Institute of Japan, Tokyo, 1991, vol. 1, pp. 465-72.

2. O. Umezawa, K. Nagai, T. Yuri, T. Ogata, and K. Ishikawa: Advances in Cryogenic Engineering Materials, Plenum Press, New York, 1992, vol. 38, pp. $175-82$.

3. P. Neumann: Acta Metall., 1969, vol. 17, pp. 1219-25.

4. O. Umezawa and K. Nagai: Iron Steel Inst. Jpn. Int., 1997, vol. 37, pp. 1170-79.

5. O. Umezawa, K. Nagai, and K. Ishikawa: in Fatigue 90, H. Kitagawa and T. Tanaka, eds., MCEP, Birmingham, United Kingdom, 1990, vol. 1, pp. 267-72.

6. I. Yamauchi: Report in Non-Magnetic Steel Research Meeting, Iron and Steel Institute of Japan, Tokyo (in Japanese), 1989, November.

7. R. Miura, H. Nakajima, Y. Takahashi, and K. Yoshida: Advances in Cryogenic Engineering Materials, Plenum Press, New York, 1984, vol. 30, pp. 245-252.

8. K. Shibata, Y. Kishimoto, N. Namura, and T. Fujita: in Fatigue at Low Temperatures, ASTM STP 857, R.I. Stephens, ed., ASTM, Philadelphia, PA, 1985, pp. 31-46.

9. T. Ogata: Report on Standardization of Testing Methods for New Energy Materials, New Material Center, Osaka, 1994, pp. 75-92 (in Japanese)

10. O. Umezawa, K. Nagai, and K. Ishikawa: Mater. Sci. Eng., 1990, vol. A129, pp. 223-27.

11. O. Umezawa, K. Nagai, and K. Ishikawa: Mater. Sci. Eng., 1990, vol. A129, pp. 217-21.

12. T. Ogata and K. Ishikawa: Trans. Iron Steel Inst. Jpn., 1986, vol. 26, pp. $48-52$

13. T. Ogata, K. Ishikawa, K. Nagai, T. Yuri, and O. Umezawa: Cryogenic Eng., 1991, vol. 26, pp. 190-96 (in Japanese).

14. K. Kanazawa, M. Kimura, and S. Nishijima: NRIM Material Strength Data Sheet-Technical Document, NRIM, Tsukuba, 1996, no. 14 (in Japanese).

15. L. Engel and H. Klingele: An Atlas of Metal Damage, Wolfe Pub. Ltd., London, 1981.

16. J.P. Bailon, J.I. Dickson, Li Shigiong, and D. Larouche: in Fatigue 90, H. Kitagawa and T. Tanaka, eds., MCEP, Birmingham, United Kingdom, 1990, vol. 3, pp. 1333-43.

17. A.P. Sutton and R.W. Balluffi: Interface in Crystalline Materials, Oxford University Press, New York, NY, 1995.

18. J.P. Hirth: Metall. Trans., 1972, vol. 3, pp. 3047-67.

19. T.C. Lee, I.M. Robertson, and H.K. Birnbaum: Phil. Mag. A, 1990, vol. 62, pp. 131-53.

20. Z. Shen, R.H. Wagoner, and W.A.T. Clark: Acta Metall., 1988, vol. 36, pp. 3231-42.

21. Z. Shen, R.H. Wagoner, and W.A.T. Clark: Scripta Metall., 1986, vol. 20, pp. 921-26.

22. J.W. Morris, Jr., S.K. Hwang, K.A. Yuschenko, V.I. Belotzerkovetz, and O.G. Kvanevskii: Advances in Cryogenic Engineering Materials, Plenum Press, New York, 1978, vol. 24, pp. 91-102.

23. Y. Tomota and S. Shibuki: Iron Steel Inst. Jpn. Int., 1990, vol. 30, pp. 663-65.

24. H. Tanaka, N. Kondo, K. Fujita, and K. Shibata: Iron Steel Inst. Jpn. Int., 1990, vol. 30, pp. 646-55.

25. A.M. Freudenthal: Eng. Fract. Mech., 1974, vol. 6, pp. 775-93.

26. O. Umezawa and K. Nagai: National Research Institute for Metals, Tsukuba, Japan, unpublished research, 1997.

27. H. Kitagawa, S. Takahashi, C.M. Suh, and S. Miyashita: in Fatigue Mechanisms, ASTM STP 675, J.T. Fong, ed., ASTM, Philadelphia, PA, 1978, pp. 420-49. 